Maksymilian Stela, Michał Ceremuga, Monika Szyposzyńska Aleksandra Spławska, Danuta Mirosz and Katarzyna Truszkowska

\title{
2. DETECTION OF CHEMICAL CONTAMINANTS
}

\subsection{Chemical Warfare Agents (CWA)}

\subsubsection{The History of Chemical Warfare (CW)}

Chemical warfare can be defined in various ways for the purposes of historical review, but primarily as the use of the toxic properties of chemical substances as weapons.

In western literature the first mention of $\mathrm{CW}$ is in Greek mythology, in which Hercules was said to have poisoned his arrows with the venom of a Hydra. In The Iliad, Homer claimed that in the Trojan War, both sides used poisoned arrows. There are also many other documented uses of early CW from ancient times. The timeline below shows not only recorded uses of chemical warfare, but also the attempts to ban it.

600 BC - The Athenian military taints the water supply of the besieged city of Kirrha with poisonous hellebore plants.

479 BC - Peloponnesian forces use sulphur fumes against the town of Plataea.

1845 - During the French conquest of Algeria, French troops force more than 1,000 members of a Berber tribe into a cave and then use smoke to kill them.

1914, August - During the first month of World War I the French deploy tear-gas grenades, first developed in 1912 for police use.

1914, October - German forces fire 3,000 shells containing dianisidine chlorosulfate, a lung irritant, at the British army at Neuve-Chapelle. The British are unaware that they have been subjected to a chemical attack because the chemical is incinerated by the explosive charge.

1915, January - The Germans fire 18,000 shells filled with the irritant xylyl bromide at Russian troops at Bolinow. The Russians are unharmed because the extreme cold keeps the liquid from vaporizing.

1915, April 22 - The German military launches the first large-scale use of chemical weapons in war at Ypres, Belgium. Nearly 170 metric tons of chlorine 
gas in 5,730 cylinders are buried along a four-mile stretch of the front. In the end more than 1,100 people are killed by the attack and 7,000 are injured.

1915, September 25 - The British military uses chemical weapons for the first time against the Germans at the Battle of Loos. They release chlorine gas from cylinders.

1915, December 19-Six days before Christmas, Germans first use phosgene on Allied troops. More than 1,000 British soldiers are injured and 120 die.

1917, July 12 - Mustard gas is used for the first time by German forces; it causes more than 2,100 casualties. During the first three weeks of mustard-gas use, Allied casualties equal the previous year's chemical-weapons casualties.

1918, June - The Allies begin using mustard gas against German troops.

1918, October 13-14 - A young Adolf Hitler, an enlisted messenger in the trenches at Werwick near Ypres, is temporarily blinded during a gas attack. Hitler is evacuated to a military hospital in eastern Germany and spends the rest of the war recuperating.

1918, November 11 - World War I ends with 1.3 million casualties caused by chemical weapons, including 90,000 to 100,000 fatalities, primarily from phosgene.

1925 - The Geneva Protocol is adopted by the League of Nations. The treaty bans the use of chemical and biological agents in war but does not prohibit the development, production, or stockpiling of such weapons. Many countries sign the treaty with reservations permitting them to respond in kind if attacked with chemical weapons.

1935-1936 - Benito Mussolini drops mustard-gas bombs in Ethiopia to destroy Emperor Haile Selassie's army. Despite Italy being a signatory of the Geneva Protocol, the League of Nations does not stop its use of chemical weapons.

1936 - German chemist Gerhard Schrader completes the synthesis and purification of tabun, a potent nerve poison. His intention is to build a pesticide, not a chemical weapon. The chemical he creates is so potent that army researchers call it taboo, or Tabu in German, from which it takes its name.

1939-1945-During World War II poison gases are used in Nazi concentration camps to kill civilians and by the Japanese army in Asia. Nerve agents are stockpiled by the Nazis, but chemical weapons are not used on European battlefields.

1953 - British serviceman Ronald Maddison dies of sarin poisoning after being purposefully exposed to the toxin at Porton Down military facility.

1961-1971 - The United States uses napalm and the herbicide Agent Orange during the Vietnam War, sparking national and international protest.

1963-1967 - Egypt uses mustard gas and a nerve agent in Yemen to support a coup d'état against the Yemeni monarchy.

1972 - The Biological and Toxin Weapons Convention is completed. Combined with the 1925 Geneva Protocol, the new accord bans the development, 
production, and possession of biological weapons. The accord has no mechanism to ensure compliance.

1980s - During the Iran-Iraq war Iraq uses chemical weapons, including tabun, against Iran and Iraq's Kurdish minority. United Nations experts confirm Iraq's use of chemical weapons, but there is little international outcry. Iran initiates its own chemical-weapons program in retaliation.

1993 - The Chemical Weapons Convention is signed. Beginning in 1997, the disarmament agreement bans the development, production, stockpiling, and use of chemical weapons.

1994, June 27 - The first successful use of Chemical Warfare Agents by terrorist in Matsumoto.

1995, March 20 - Terrorist attack in Tokyo subway with sarin.

2013 - The Syrian military uses sarin gas against civilians during the Syrian Civil War; hundreds are killed. Bashar al-Assad's government relinquishes its arsenal of chemical weapons after threats of U.S. air strikes.

2017, February 13 - Kim Dzong Nam assassinated with VX.

Although chemicals had been used as tools of war for thousands of years, as can be seen above modern chemical warfare had its genesis on the battlefields of World War I.

The use of several different types of chemical weapons, including mustard gas (also known as yperite), resulted in 90,000 deaths and over one million casualties during the war.

Surprisingly, despite extensive preparations by all sides, CW wasn't used on a large scale in WW II. Historians are still debating why, with one explanation being the mutual fear of massive chemical counter-attacks. Some historians say that Hitler was adverse to using mustard gas since he had himself been a mustard victim in WW I.

Throughout history there have been several attempts to ban CW, with limited success. One example is an Italian gas attack in Ethiopia, when Mussolini dropped mustard bombs despite Italy having signed the Geneva Protocol.

A significant improvement came with the "Convention on the Prohibition of the Development, Production, Stockpiling and Use of Chemical Weapons and on their Destruction', better known in its shorter version, the Chemical Weapon Convention (CWC). This is an arms control treaty that outlaws the production, stockpiling and use of chemical weapons and their precursors. Thanks to this Convention, a chemical weapon demilitarization process was begun in 1997. For the purposes of implementation and verification of the CVC, The Organisation for the Prohibition of Chemical Weapons (OPCW) was created in April 1997. By the end of 2016, 67,098 metric tonnes (90\% of the world's declared stockpile of 72,304 metric tonnes of chemical agents), have been verifiably destroyed.

On October the $11^{\text {th }}, 2013$, the Norwegian Nobel Committee announced that the OPCW had been awarded the Nobel Peace Prize for "extensive work to eliminate chemical weapons". 


\subsubsection{Definition of CWA}

In the previoussection ashort definition of Chemical Warfare was presented, and this section will look at Chemical Warfare Agents. Wikipedia states that "A chemical weapon agent (CWA) is a chemical substance whose toxic properties are used to kill, injure or incapacitate human beings".

A similar definition is proposed by the Federation of American Scientists (FAS): "A chemical agent is a substance which is intended for use in military operations to kill, seriously injure or incapacitate people because of its physiological effects. Excluded from this definition are riot control agents, herbicides, smoke, and flame".

A little wider definition is proposed by Satu M. Somani, a Professor of Pharmacology and leading expert in the field, who states that "Chemical Warfare Agents are chemicals that have direct toxic effects on humans, animals and plants". A much broader definition, which by necessity is also much more precise (to avoid misunderstandings at the international level), is included in the CWC, in Article II. Definitions and Criteria:

1. "Chemical Weapons" means the following, together or separately:

(a) Toxic chemicals and their precursors, except where intended for purposes not prohibited under this Convention, as long as the types and quantities are consistent with such purposes;

(b) Munitions and devices, specifically designed to cause death or other harm through the toxic properties of those toxic chemicals specified in subparagraph (a), which would be released as a result of the employment of such munitions and devices;

(c) Any equipment specifically designed for use directly in connection with the employment of munitions and devices specified in subparagraph (b)."

To clarify what toxic chemical and precursor is:

2. “Toxic Chemical” means:

Any chemical which through its chemical action on life processes can cause death, temporary incapacitation or permanent harm to humans or animals. This includes all such chemicals, regardless of their origin or of their method of production, and regardless of whether they are produced in facilities, in munitions or elsewhere.

3. "Precursor" means:

Any chemical reactant which takes part at any stage in the production by whatever method of a toxic chemical. This includes any key component of a binary or multicomponent chemical system.

A full list of chemicals covered by the CWC is published in its 'Annex on Chemicals', in which all substances are classified into three 'schedules', with the first being the most dangerous.

Definitions of chemicals are often 'open', which means that only their properties or general structure are defined. For example, in Schedule 2.B.4 - Chemicals, apart from the items listed in Schedule 1, there is a phosphorus atom to which is bonded 
one methyl, ethyl or propyl (normal or iso) group, but no further carbon atoms. The definition of this atom is so open, that the estimated number of possible chemicals that can be derived from it is countable in the millions.

\subsubsection{Classification of CWA}

CWAs possess different characteristics and belong to various classes of compounds with pronounced physicochemical, physiological and chemical properties. As such, they can also be classified by their physical state - gaseous, liquid or solid.

Based on their volatility, they are then classified as persistent or non-persistent agents. The more volatile an agent, the quicker it evaporates and disperses. The more volatile agents, such as chlorine, phosgene and hydrogen cyanide, are nonpersistent agents, whereas the less volatile agents, such as sulphur mustard and Vx are persistent agents.

Chemical Warfare Agents with a boiling point below $130^{\circ} \mathrm{C}$ are usually regarded as volatile, those with boiling points between $150^{\circ} \mathrm{C}$ and $300^{\circ} \mathrm{C}$ as persistent. For example, Phosgene has a boiling point of $7.5^{\circ} \mathrm{C}$ and is considered volatile, while VS has a boiling point of $300^{\circ} \mathrm{C}$ and is considered highly persistent.

CWAs can also be classified based on their chemical structure as organophosphorus, an organosulfur or organofluorine compounds and arsenicals.

However, the best known classification system is based on their effect on humans, as follows:

1. Nerve agents;

2. Vesicants (blistering agents);

3. Bloods agents (cyanogenic agents);

4. Choking agents (pulmonary agents);

5. Riot-control agents (tear gases);

6. Psychomimetic agents;

7. Toxins.

\section{Nerve agents}

Nerve agents are named for their effect on the functioning of the nervous system. They do not occur naturally, but belong to the group of OP compounds (organic compounds containing phosphorus). Generally, nerve agents are more toxic than other CWAs. They are highly toxic and can cause death from within a few minutes to a few hours after exposure, depending on the concentration. The first known nerve agent, Tabun (GA), was first developed in the 1930s by the German chemist, Gerhard Schrader, in his research on the development of new OP insecticides. Following this, a series of nerve agents known as G-agents, which include Sarin (GB) and Soman (GD), were developed. Historically, Germany maintained stockpiles of nerve agent 
munitions during World War II, but did not use them. A variety of nerve agents were then developed for military use, up to the 1960s. The focus was on increasing their potency and environmental persistence, which led to V-agents - more stable versions of G-agents. These include VX, a sulphur-containing OP, which is more potent than sarin, more stable, less volatile and less water-soluble, acts through direct skin contact and persists in the environment for up to several weeks after release.

The only known battlefield use of nerve agents was in the Iran-Iraq conflict in 1980-1998; Iraq reportedly used nerve agents against Iranian troops and later against members of its Kurdish population in northern Iraq.<smiles>CCOP(C)(C)=O</smiles>

Tabun (GA)<smiles>CC(OP(C)(=O)F)C(C)(C)C</smiles>

Soman (GD)<smiles>CCOP(C)(=O)SCCN(C(C)C)C(C)C</smiles>

VX

Sarin (GB)

Figure 1. Chemical structure of nerve agents

\begin{tabular}{lcccc}
\hline & Tabun & Sarin & Soman & VX \\
\hline Molecular weight & 162.12 & 140.09 & 182.19 & 267 \\
Vapor density (air $=1$ ) & 5.63 & 4.86 & 5.6 & 7.29 \\
Liquid density $\left(\mathrm{g} / \mathrm{cm}^{3}, 25^{\circ} \mathrm{C}\right)$ & 1.07 & 1.102 & 1.02 & 1.062 \\
Melting point $\left({ }^{\circ} \mathrm{C}\right)$ & -50 & -57 & -42 & -51 \\
Boiling point $\left({ }^{\circ} \mathrm{C}\right.$ ) & 248 & 147 & 198 & 298 (decom.) \\
Vapor pressure $\left(\mathrm{mmHg}, 25^{\circ} \mathrm{C}\right)$ & 0.037 & 2.9 & 0.40 & 0.0007 \\
Volatility $\left(\mathrm{mg} / \mathrm{m}^{3}\right.$ at $\left.25^{\circ} \mathrm{C}\right)$ & 610 & 22,000 & 3,900 & 75 \\
$\mathrm{LD}_{50}(\mathrm{skin}, \mathrm{mg} / \mathrm{kg})$ & $1-1.5$ & 24 & $10-15$ & $<5$ \\
$\mathrm{LCt}_{50}\left(\right.$ respiratory, $\left.\mathrm{mg}-\mathrm{min} / \mathrm{m}^{3}\right)$ & $135-400$ & $70-100$ & $70-400$ & 30 \\
\hline
\end{tabular}

Figure 2. Properties of nerve agents (figure used with permission under Creative Commons license) 
Other examples of popular nerve agents include tabun, which is a stable, colourless to brownish liquid (depending on the purity level), and is odourless (but can obtain a faint fruity odour from impurities). Sarin is also a colourless to yellow-brown liquid that is either odourless or smells slightly fruity, and is about 20 times more volatile than tabun. Soman has a similar colour and odour as tabun and sarin, but is more persistent than sarin. When impure, it has a strong camphorous odour. VX is colourless and odourless, but can obtain an amber colour of formulated as an oily liquid. It has the lowest vapour pressure of all nerve agents and is therefore one of the more persistent chemical warfare agents.

\section{Mechanism of action}

The primary mechanism of toxicity results from inhibition of the enzyme acetylcholinesterase (AChE) at the neuromuscular junction, which causes overstimulation of the muscles through the excessive accumulation of the neurotransmitter acetylcholine $(\mathrm{ACh})$. This over stimulation results in muscle paralysis.

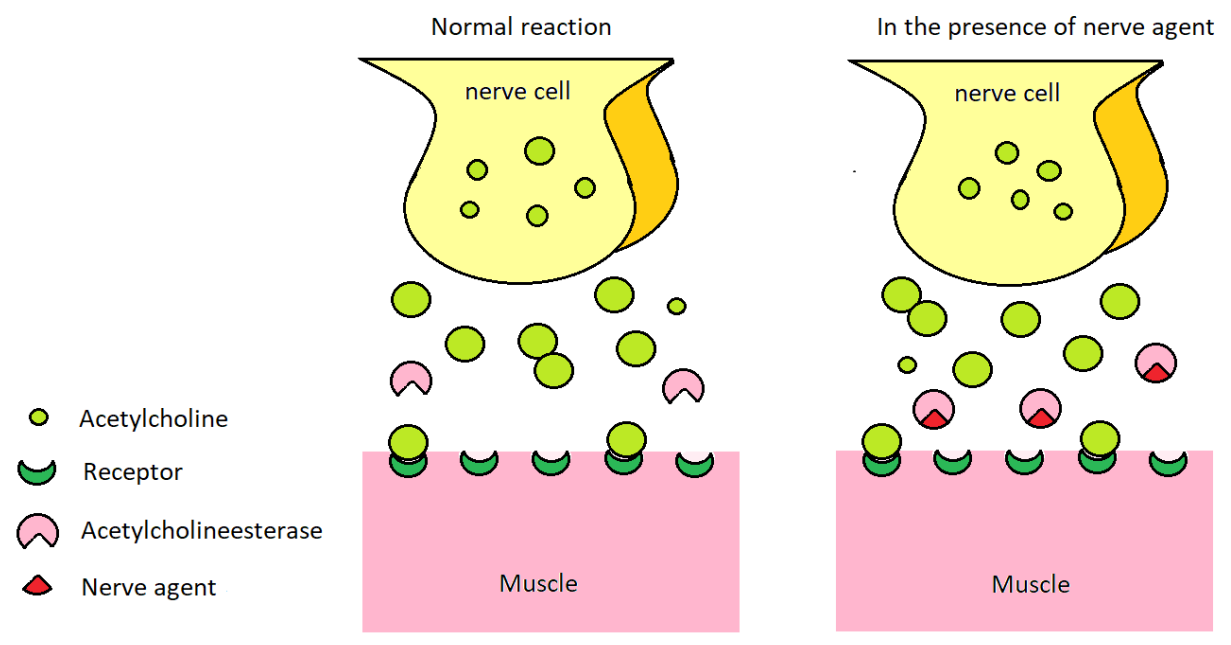

Figure 3. Mechanism of a nerve agent's action

Figure 3 presents a simplified picture of a cholinergic synapse, with the nerve in which acetylcholine is formed, and the receiving side (muscles, glands etc.) with receptors. Acetylcholine is formed and released from the nerve cell. On the other side of the synapse it binds to a muscle cell receptor for a split second. The signal to, for example, bend an arm or take a breath has now been transferred from the nervous system to the performing muscle. But in the presence of a nerve 
agent, the enzyme acetylcholinesterase, which is responsible for breaking down acetylcholine, is inhibited. The receptor then keeps on sending signals to the muscle cell, and this leads to muscle cramp.

\section{Blistering agents}

Blistering agents, or vesicants, are toxic compounds that produce skin injuries resembling burns. Upon inhalation, these agents affect the upper respiratory tract as well as the lungs, producing pulmonary oedema. These agents can also cause severe eye injuries. There are two forms of vesicants: mustards and arsenicals. The most important substance in this class of CWA is sulphur mustard, otherwise known as the king of $\mathrm{CW}$ agents. Other members include nitrogen mustards ( HN1, HN2 and HN3), and lewisites (L1, L2 and L3).

$$
\text { S- }{ }_{\mathrm{CH}_{2} \mathrm{CH}_{2} \mathrm{Cl}}^{\mathrm{CH}_{2} \mathrm{CH}_{2} \mathrm{Cl}}
$$

Sulphur mustard (HD)
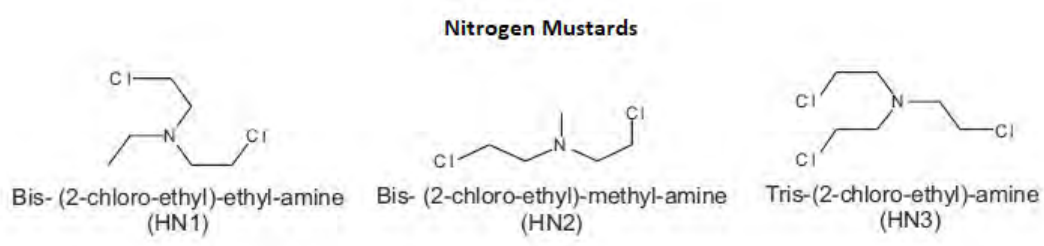

Lewisites

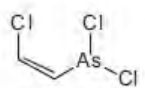

(2-Chlorovinly) dichloroarsine (L1)

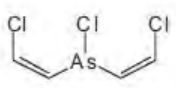

Bis (2-Chlorovinyl) chloroarsine (L2)

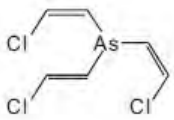

Tris (2-Chlorovinyl) arsine (L3)

Figure 4. Chemical structures of blister agents

Mustard gas (yperite, sulphur mustard, H, HD) is odourless and colourless when pure, but in its impure form is a yellow-brown oily liquid with the odour of mustard or horseradish. Due to its high melting point of $14{ }^{\circ} \mathrm{C}$ it is not suitable for use during winter, but when mixed with Lewisite (63\% Lewisite and 37\% mustard), the melting point is lowered to $-14^{\circ} \mathrm{C}$.

Of the $\mathrm{N}$-mustards ( $\mathrm{HN}-1, \mathrm{HN}-2, \mathrm{HN}-3), \mathrm{HN}-1$ is suitable for use at lower temperatures. The odour of $\mathrm{HN}-1$ and $\mathrm{HN}-3$ is fishy, whereas higher 
concentrations of $\mathrm{HN}-2$ smell fruity. All mustards can easily penetrate rubber, textiles and leather, as well as porous materials such as bricks and concrete.

Lewisite is the main arsenic blister agent. When impure, this colourless liquid has a geranium-like odour.

\section{Mechanism of action}

The toxic effects of a mustard agent depend on its ability to covalently bind to other substances. The chlorine atom is spiked off the ethyl group and the mustard agent is transferred to a reactive sulfonium ion. This ion can bind to a large number of different biological molecules. Most of all, it binds to nucleophiles such as nitrogen in the base components of nucleic acids, and sulphur in SH-groups in proteins and peptides. Since mustard agents contain two 'reactive groups', they can also form a bridge between or within molecules. Mustard agents can destroy a large number of different substances in the cell by means of alkylation, and thereby influence numerous processes in living tissue.

Nitrogen mustards form cyclic aminium ions (aziridinium rings) through intramolecular displacement of the chloride by the amine nitrogen. This aziridinium group then alkylates DNA when it is attacked by the N-7 nucleophilic centre on the guanine base. A second attack after the displacement of the second chlorine forms the second alkylation step, which results in the formation of inter-strand cross-links.

\section{Blood agents}

Like the other groups of agents, blood agents derive their name from their effect. Blood agents are distributed via the blood, and generally enter the body via inhalation. They inhibit the ability of blood cells to utilise and transfer oxygen. Thus, blood agents are poisons that effectively cause the body to suffocate.

\begin{tabular}{lcc}
\hline & $\begin{array}{c}\text { Hydrogen cyanide } \\
\text { (AC) }\end{array}$ & $\begin{array}{c}\text { Cyanogen chloride } \\
\text { (CK) }\end{array}$ \\
\hline Molecular weight & 27.03 & 61.48 \\
Vapor density (air $=1$ ) & 1.007 & 2.1 \\
Liquid density $\left(\mathrm{g} / \mathrm{cm}^{3}, 20^{\circ} \mathrm{C}\right)$ & 0.687 & 1.18 \\
Melting point $\left({ }^{\circ} \mathrm{C}\right)$ & -13.3 & -6.9 \\
Boiling point $\left({ }^{\circ} \mathrm{C}\right.$ ) & 25.7 & 12.8 \\
Vapor pressure $\left(\mathrm{mmHg}^{\circ} 25^{\circ} \mathrm{C}\right)$ & 742 & 1,000 \\
Volatility $\left(\mathrm{mg} / \mathrm{m}^{3}\right.$ at $25^{\circ} \mathrm{C}$ ) & $1,080,000$ & $2,600,000$ \\
$\mathrm{LD}_{50}$ (skin, $\mathrm{mg} / \mathrm{kg}$ ) & 100 (liquid) & No data available \\
$\mathrm{LCt}_{50}$ (respiratory, $\left.\mathrm{mg}-\mathrm{min} / \mathrm{m}^{3}\right)$ & 2,000 & 11,000 \\
\hline
\end{tabular}

Figure 5. Properties of blood agents (figure used with permission under Creative Commons license) 
Hydrogen cyanide is a transparent, colourless and easily water-soluble liquid that has a bitter almond odour that, due to genetic predisposition, cannot be sensed by everybody. Its very high volatility leads to difficulties in achieving lethal combat concentrations on the battlefield, but is still very dangerous in enclosed spaces. As such, it is mainly used as a terrorist weapon.

Cyanogen chloride is also a colourless liquid with a low boiling point, is highly irritant to the mucous membranes and causes severe tear flow. It also has an almond aroma and can penetrate the filter elements of a gas mask more readily than any other agent.

\section{Mechanism of action}

Cyanide has a very high affinity with iron in the ferric $\left(\mathrm{Fe}^{+3}\right)$ state. On entering the biological system, it readily reacts with trivalent iron of cytochrome oxidase (an end-chain enzyme of cellular respiration) to form a complex, thereby impairing the utilization of oxygen in the tissues. Eventually, death follows as a result of respiratory failure. The onset and intensity of symptoms depend on the concentration of inhaled toxic vapour and duration of exposure. Symptoms of exposure to low doses of HCN are weakness, giddiness, headache, confusion, and sometimes nausea and vomiting.

\section{Choking agents}

Choking agents mainly affect the respiratory tract, i.e. the nose, throat, and particularly the lungs. Choking agents were among the first CW agents produced in large quantities and were used extensively in World War I. They are generally heavier than air. Phosgene is used in many chemical industrial processes, making the control of these compounds difficult, and these can be used as a devastating low-tech weapon in the hands of terrorists. Phosgene is a colourless gas with the odour of cut grass or hay, and is highly volatile due its low boiling point. It is three times as heavy as air, and so accumulates in depressions, holes and cellars. Diphosgene is the colourless to yellow-brownish liquid form of phosgene, and has a higher boiling point.

\begin{tabular}{|c|c|c|}
\hline & Phosigene (CG) & Diphosgene (DP) \\
\hline Molecular weight & 98.92 & 197.85 \\
\hline Vapor density (air $=1$ ) & 3.4 & 6.8 \\
\hline Liquid density $\left(\mathrm{g} / \mathrm{cm}^{3}, 25^{\circ} \mathrm{C}\right)$ & 1.381 & 1.65 \\
\hline Melting point $\left({ }^{\circ} \mathrm{C}\right)$ & -128 & -57 \\
\hline Boiling point $\left({ }^{\circ} \mathrm{C}\right)$ & 7.6 & 128 \\
\hline Vapor pressure $\left(\mathrm{mm} \mathrm{Hg}, 25^{\circ} \mathrm{C}\right)$ & 1,180 & 4.2 \\
\hline Volatility $\left(\mathrm{mg} / \mathrm{m}^{3}\right)$ & $4,300,000$ (at $7.6^{\circ} \mathrm{C}$ ) & 45,000 \\
\hline LCt $_{30}$ (respiratory, mg-min/ms) & 3,200 & $3,000-3,200$ \\
\hline
\end{tabular}

Figure 6. Properties of phosgene and diphosgene (figure used with permission under Creative Commons license). 


\section{Mechanism of action}

Phosgene is highly reactive and combines with the $-\mathrm{SH},-\mathrm{NH}_{2}$ and $-\mathrm{OH}$ groups of biological macromolecules, including enzymes, and this may account for its toxic effects. Poisoning is mainly attributed to acylation of certain tissue elements of the lungs, and increased permeability of the alveolar mucous membrane. This results in pulmonary oedema with consequent anoxia and death. Inhalation of low concentrations of phosgene produces rapid, shallow breathing, reduced respiratory volume, bradycardia and hypotension. Many cholinergic symptoms, such as increased salivation, nausea, micturition and defecation are also observed.

\section{Riot-control agents}

Riot control agents (RCA) are compounds that cause temporaryincapacitation by irritation of the eyes (tearing and blepharospasm), causing them to close, and irritation of the upper respiratory tract. Technically, they are irritants, lachrymators and harassing agents, although they are general all considered 'tear gas'.

The classification of riot-control agents as CWAs is confusing. According to the Organisation for the Prevention of Chemical Warfare, state-level entities should declare their RCA stocks used for law enforcement purposes. Though their use is allowed for such, it is prohibited in warfare.

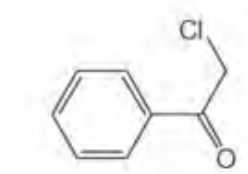

2-Chloroacetophenone (CN)

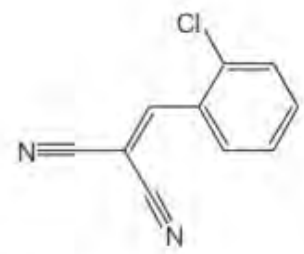

2-Chlorobenzilidenemalononitrile (CS)

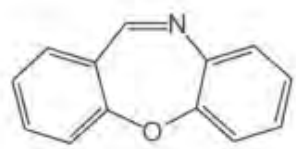

Dibenz (b, f)-1,4-oxazepine (CR)

Figure 7. Chemical structures of riot control agents

\begin{tabular}{|c|c|c|c|}
\hline & $\mathrm{CN}$ & CS & CR \\
\hline Molecular weight & 154.59 & 188.61 & 195 \\
\hline Vapor density (air $=1$ ) & 5.3 & 6.5 & 6.7 \\
\hline Melting point $\left({ }^{\circ} \mathrm{C}\right)$ & 54 & 94 & 72 \\
\hline Vapor pressure at $20^{\circ} \mathrm{C}(\mathrm{mmHg})$ & $5.4 \times 10^{-3}$ & $3.4 \times 10^{-6}$ & $5.9 \times 10^{-5}$ \\
\hline Volatility at $25^{\circ} \mathrm{C}\left(\mathrm{mg} / \mathrm{m}^{3}\right)$ & 34 & 0.71 & 0.63 \\
\hline LCt50 (respiratory, mg-min/m') & $7,000-14,000$ & 61,000 & Not available \\
\hline
\end{tabular}

Figure 8. Properties of RCAs (figure used with permission under Creative Commons license) 
At room temperature, $\mathrm{CN}, \mathrm{CS}$ and $\mathrm{CR}$ are colourless crystals that can be dispersed as aerosols. The compounds are thermally stable, resistant to detonation and can be mixed with other warfare agents.

\section{Mechanism of action}

For each of the acute symptoms of pain, the probable mode of action is a direct chemical attack on sensory receptors in the skin and mucosa that involves a nicotinamide adenine dinucleotide hydrogenase (NADH)-dependent enzymatic process. The peripheral nature of their site of action distinguishes these agents pharmacologically from other incapacitating agents that affect the central nervous system, such as psychochemicals.

\section{Psychomimetic agents}

This group of CWAs usually includes substances that, when administered in low doses $(<10 \mathrm{mg})$, cause effects similar to psychotic disorders or other symptoms of damage to the the central nervous system (loss of feeling, paralysis, rigidity etc.).

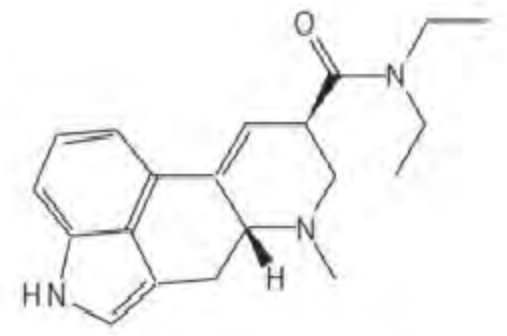

lysergic acid diethylamide

(LSD)

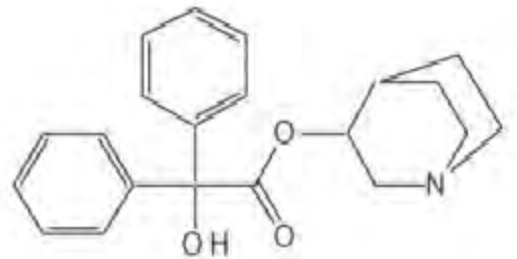

3-quinuclidinyl benzilate

$(\mathrm{BZ})$

Figure 9. Chemical structures of psychomimetic agents

From a military point of view, $\mathrm{BZ}$ is the most important psychomimetic as it can be easily produced. BZ was weaponized during the 1960s. It is a nearly odourand colourless crystalline powder with a high boiling point and low volatility.

Mechanism of action

$\mathrm{BZ}$ interferes with cholinergic nerve transmission at muscarinic sites, both in the peripheral autonomic nervous system and in the brain and spinal cord. BZ readily crosses the blood-brain barrier, and is distributed to all areas of receptors 
as a competitor with the physiologically active transmitter acetylcholine. In the central nervous system, BZ bonds to all subtypes of muscarinic receptors, each of them having different functions in the brain.

\section{Toxins}

Poisonous chemical compounds synthesized in nature by living organisms such as bacteria, fungi, terrestrial and marine animals are called toxins. These are classified on the basis of their chemical nature, molecular weight, source, preferred targets in the body and mechanism of action. As such, there are two groups: protein toxins consisting of long, folded chains of amino acids, and non-protein toxins, which are generally small molecules with a complex chemical nature. Because of the hybrid nature of toxins, they have sometimes been considered CWAs and sometimes BWAs (Biological Warfare Agents). Based on their mechanism of action, they are classified either as cardiotoxins, dermatotoxins, hepatotoxins, neurotoxins, etc. The most potent toxins are neurotoxins, such as the botulinum toxin and tetanus toxin, but there are others potent toxins, such as the staphylococcal enterotoxin.

\begin{tabular}{llcl}
\hline Origin & Toxin & $\begin{array}{c}\mathrm{LD}_{50} \\
(\mu \mathrm{g} / \mathrm{kg})\end{array}$ & Mode of action \\
& & (approx. $)$ & \\
\hline Bacteria & Botulinum toxin & 0.0001 & Neurotoxin \\
& Tetanus toxin & 0.001 & Neurotoxin \\
& Staphylococcus & 2,000 & Membrane damaging \\
Fungi & Enterotoxins B & & Interference with regulation \\
& Tricothecenes & 3,000 & Inhibition of protein \\
& Aflatoxin & 5,000 & synthesis \\
Algae & & & Inhibition of nucleic acid \\
Cyanobacteria & Anatoxin & 200 & Neurotoxin \\
Dinoflagellates & Microcystins & 40 & Hepatotoxin \\
& Brevetoxin & 10 & Neurotoxin \\
& Saxitoxin & 5 & Neurotoxin \\
Plant & Ricin & 0.01 & Inhibition of protein \\
& Abrin & 0.01 & synthesis \\
& & & Inhibition of protein \\
& & & synthesis \\
Animal & Batrachotoxin & 0.06 & Neurotoxin \\
& Palytoxin & 0.15 & Cardiotoxin \\
& Snake venoms & 0.20 & Hemolytic or neurotoxin \\
\hline
\end{tabular}

Figure 10. Characteristics of several potent toxins (figure used with permission under Creative Commons license) 


\subsection{Toxic Industrial Chemicals}

\subsubsection{Description of Toxic Industrial Chemicals (TIC)}

The term 'toxic industrial chemicals' covers a variety of chemicals used or produced by industry that can have a significant impact on human health if released into the air or water. According to the Chemical Weapon Convention, any TIC can be considered a chemical weapon if it is designed or used for military purposes. In the past, most CWAs consisted of TICs (chlorine, phosgene, hydrogen cyanide, chloropicrin, etc.), or were developed in the context of civilian research and development (for example, nerve agents). The main risk of TICs is that they are manufactured and stored in vast quantities and can be relatively easily used in international or domestic armed conflicts. A general limitation of the production and consumption of TICs is extremely difficult for various reasons. Toxic Industrial Chemicals include certain unusual compounds that are of interest to experts in chemical weapons. For example, dioxin (2,3,7,8-tetrachlorodibenzo-p-dioxin, TCDD) and its analogues. TCDD is well known as an impurity in herbicides (for example, Agent Orange), and is equally well known for its use in the Vietnam war. Experts also remember its part in a 1976 industrial accident in Seveso, Italy. It is, basically, an extremely toxic synthetic agent capable of alkylating various cellular polymers, including DNA. Some of the clinical symptoms of TCDD poisoning are similar to mustard gas. TCDD has a long latency period, and its effects are difficult to treat. It is ideal in ecological warfare, because it can cause long-term and dangerous contamination of large areas, even when used in relatively low concentrations.

\subsubsection{Classification}

Toxic Industrial Chemicals can be both organic and inorganic chemicals and have small or large molecular weight, so their classification is difficult. There have been many attempts to define a list of potential dangerous TICs. One of the most commonly used is based on the Hazard Index (HI).

Chemicals with $\mathrm{HI} \geq 90$ are listed in the high risk group; those with $\mathrm{HI}$ between 36 and 89 are in the medium hazard group, and below 36 in the low hazard group. Use of toxic industrial chemicals is sometimes considered; chemical warfare without chemical weapons. The Hazard Index is a good index for characterising overall, global danger from toxic chemicals. But it must be remembered that from even mildly toxic chemicals, much more hazardous materials can be extrapolated, deliberately or inadvertently. The 1984 Bhopal Disaster in Bhopal, India, is considered the most catastrophic CBRN incident ever, and had even worse consequences than the reactor meltdown in Chernobyl-and it was caused by Methyl isocyanate, a medium-class TIC. 


\begin{tabular}{lclccccc}
\hline $\begin{array}{c}\text { Toxicity } \\
\text { (IDLH } \\
\text { in ppm) }\end{array}$ & Index & $\begin{array}{c}\text { State } \\
\text { (Vapor Pressure } \\
\text { in } \mathbf{m m H g})\end{array}$ & Index & Distributiona & Index & $\begin{array}{c}\text { Number of } \\
\text { Producers }\end{array}$ & Index \\
\hline$<1$ & 5 & Gas & 5 & $5 / 6$ & 5 & $>100$ & 5 \\
1 to 10 & 4 & Liquid: $>400$ & 4 & 4 & 4 & 50 to 99 & 4 \\
11 to 100 & 3 & $\begin{array}{l}\text { Liquid: } 100 \text { to } \\
\text { <400 }\end{array}$ & 3 & 3 & 3 & 25 to 49 & 3 \\
101 to 500 & 2 & Liquid: 10 to $<100$ & 2 & 2 & 2 & 5 to 24 & 2 \\
$>500$ & 1 & Liquid: $<10$ & 1 & 1 & 1 & $<5$ & 1 \\
\hline
\end{tabular}

a Number of continents in which production occurs.

Figure 11. Hazard Index Parameters (figure used with permission under Creative Commons license)

\subsubsection{The Globally Harmonized System of Classification and Labelling of Chemicals (GHS)}

The GHS defines and classifies the hazards of chemical products, and communicates health and safety information on labels and safety data sheets. The goal is to have the same set of rules for classifying hazards, and the same format and content for labels and safety data sheets (SDS), adopted and used around the world. An international team of hazard co0mmunication experts developed the GHS, which covers all hazardous chemicals and can be adapted to cover chemicals in the workplace, in transport, consumer products, pesticides and pharmaceuticals. The target audiences for GHS include workers, transport workers, emergency responders and consumers. The two major elements of GHS are:

1. Classification of the hazards of chemicals according to the GHS rules: the GHS provides guidance on classifying pure chemicals and mixtures according to its own criteria.

2. Communication of hazards and precautionary information using Safety Data Sheets and labelling.

3. Safety Data Sheets - GHS Safety Data Sheets have 16 sections, laid out in a set order, with space for the minimum prescribed information.

4. Labels - certain information will always appear on the label. For example, the chemical identity. Appropriate standardized hazard statements, signal words and symbols will also appear, as well as precautionary statements, if required by the relevant regulatory authority.

In the European Union, the GHS was implemented via the 2008 CLP (Classification, Labelling and Packaging) Regulation.

The GHS also introduces unified criteria for chemical classification, and introduces three classes of hazard:

- Physical hazards;

- Health hazards;

- Environmental hazards. 
Within the GHS, two sets of pictograms are included: one for the labelling of containers and for workplace hazard warnings, and the other for use during the transport of dangerous goods. Either one or the other is used, but not both at the same time. The two sets of pictograms use the same symbols for the same hazards, although certain symbols are not required for transport pictograms. Transport pictograms also come in wider variety of colours and may contain additional information, such as a subcategory number.

Table 1. GHS hazard pictograms (non-transport)

\begin{tabular}{|l|l|l|}
\hline Description & \multicolumn{1}{|c|}{ Hazard class and hazard category } \\
\hline $\begin{array}{l}\text { Exploding } \\
\text { Bomb }\end{array}$ & $\begin{array}{l}\text { Unstable explosives Explosives of Divisions 1.1, } \\
\text { 1.2, 1.3, 1.4 Self-reactive substances and mixtures, } \\
\text { Types A,B Organic peroxides, Types A,B }\end{array}$ \\
\hline Flame & $\begin{array}{l}\text { Flammable gases, category 1 Flammable aerosols, } \\
\text { categories 1,2 Flammable liquids, categories 1,2,3 } \\
\text { Flammable solids, categories 1,2 Self-reactive sub- } \\
\text { stances and mixtures, Types B,C,D,E,F Pyrophoric } \\
\text { liquids, category 1 Pyrophoric solids, category } 1 \\
\text { Self-heating substances and mixtures, categories } \\
\text { 1,2 Substances and mixtures, which in contact } \\
\text { with water, emit flammable gases, categories 1,2,3 } \\
\text { Organic peroxides, Types B,C,D,E,F }\end{array}$ \\
\hline Flame Over & $\begin{array}{l}\text { Oxidizing gases, category 1 Oxidizing liquids, } \\
\text { categories 1,2,3 }\end{array}$ \\
\hline Gircle & $\begin{array}{l}\text { Gases under pressure: - Compressed gases - Liq- } \\
\text { uefied gases - Refrigerated liquefied gases - Dis- } \\
\text { solved gases }\end{array}$ \\
\hline
\end{tabular}




\begin{tabular}{|c|c|c|}
\hline Description & Pictogram & Hazard class and hazard category \\
\hline Corrosion & & $\begin{array}{l}\text { Corrosive to metals, category } 1 \text { Skin corrosion, cat- } \\
\text { egories } 1 \mathrm{~A}, 1 \mathrm{~B}, 1 \mathrm{C} \text { Serious eye damage, category } 1\end{array}$ \\
\hline $\begin{array}{l}\text { Skull and } \\
\text { Crossbones }\end{array}$ & & $\begin{array}{l}\text { Acute toxicity (oral, dermal, inhalation), categories } \\
1,2,3\end{array}$ \\
\hline $\begin{array}{l}\text { Exclama- } \\
\text { tion Mark }\end{array}$ & & $\begin{array}{l}\text { Acute toxicity (oral, dermal, inhalation), category } \\
4 \text { Skin irritation, category } 2 \text { Eye irritation, catego- } \\
\text { ry } 2 \text { Skin sensitisation, category } 1 \text { Specific Target } \\
\text { Organ Toxicity - Single exposure, category } 3\end{array}$ \\
\hline $\begin{array}{l}\text { Health } \\
\text { Hazard }\end{array}$ & & $\begin{array}{l}\text { Respiratory sensitization, category } 1 \text { Germ cell } \\
\text { mutagenicity, categories 1A,1B,2 Carcinogenicity, } \\
\text { categories 1A,1B,2 Reproductive toxicity, cate- } \\
\text { gories 1A,1B,2 Specific Target Organ Toxicity } \\
\text { - Single exposure, categories 1,2 Specific Target } \\
\text { Organ Toxicity - Repeated exposure, categories } \\
\text { 1,2 Aspiration Hazard, category } 1\end{array}$ \\
\hline $\begin{array}{l}\text { Environ- } \\
\text { ment }\end{array}$ & & $\begin{array}{l}\text { Hazardous to the aquatic environment - Acute } \\
\text { hazard, category } 1 \text { - Chronic hazard, categories } 1,2\end{array}$ \\
\hline
\end{tabular}

When done properly, the labelling of chemicals is a powerful tool for identification of chemicals and hazards. Transport labels are defined in more detail in the ADR ( $L^{\prime}$ Accord européen relatif au transport international des marchandises Dangereuses par Route), which is another great source of information, especially for firefighters and HAZMAT Teams.

In addition, some very helpful tools are easily accessible to anyone with a smartphone (Android, iOS, Windows), in the form of the many apps available 
that list all kinds of information about chemicals, identified by their UN numbers, including their toxicology, potential hazard, treatments etc.

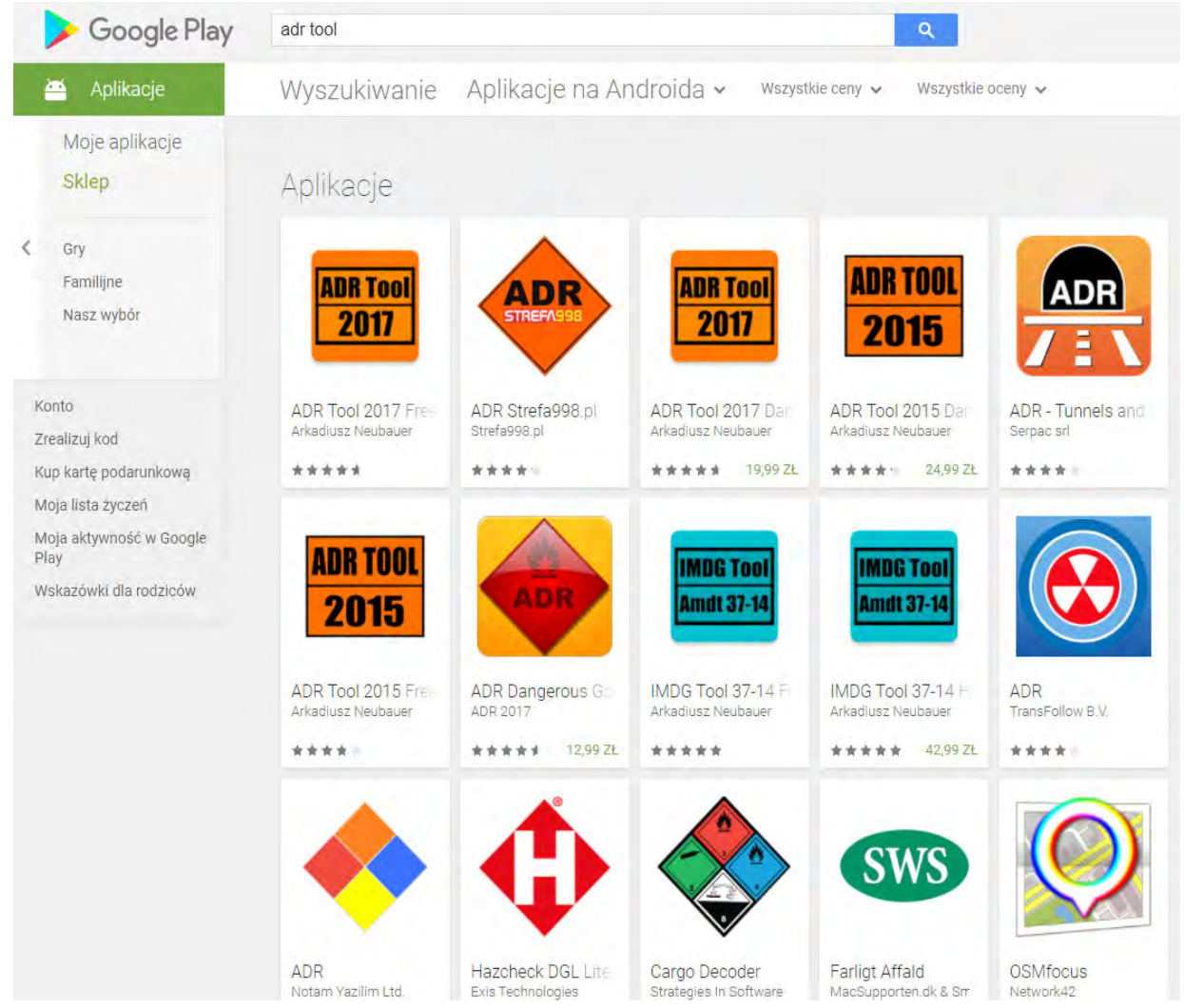

Figure 12. Some of the Android ADR apps

\subsection{Chemical detection and identification techniques and equipment}

\subsubsection{Colorimetric detectors}

Colorimetric detectors analyse the colour change resulting from the reaction between a targeted chemical and reagents. This technique has many different applications. One very well-known example of colorimetric detection is the use of litmus paper to test $\mathrm{pH}$. Colorimetric detectors often take the form of badges and tubes, with which the signal (colour change) is detected by the naked eye, instead of with an electronic readout or device. Therefore, most colorimetric 
detectors can be made very small and simple, are less costly to produce and do not need electric power for operation.

Detectors are made with a sorbent substrate, paper, paper tape or a glass tube impregnated with colorimetric reagent(s), which react with a specifically targeted chemical to form a particular colour. Colorimetric tubes can consist of finely impregnated beads, together with the necessary reagent ampoules.

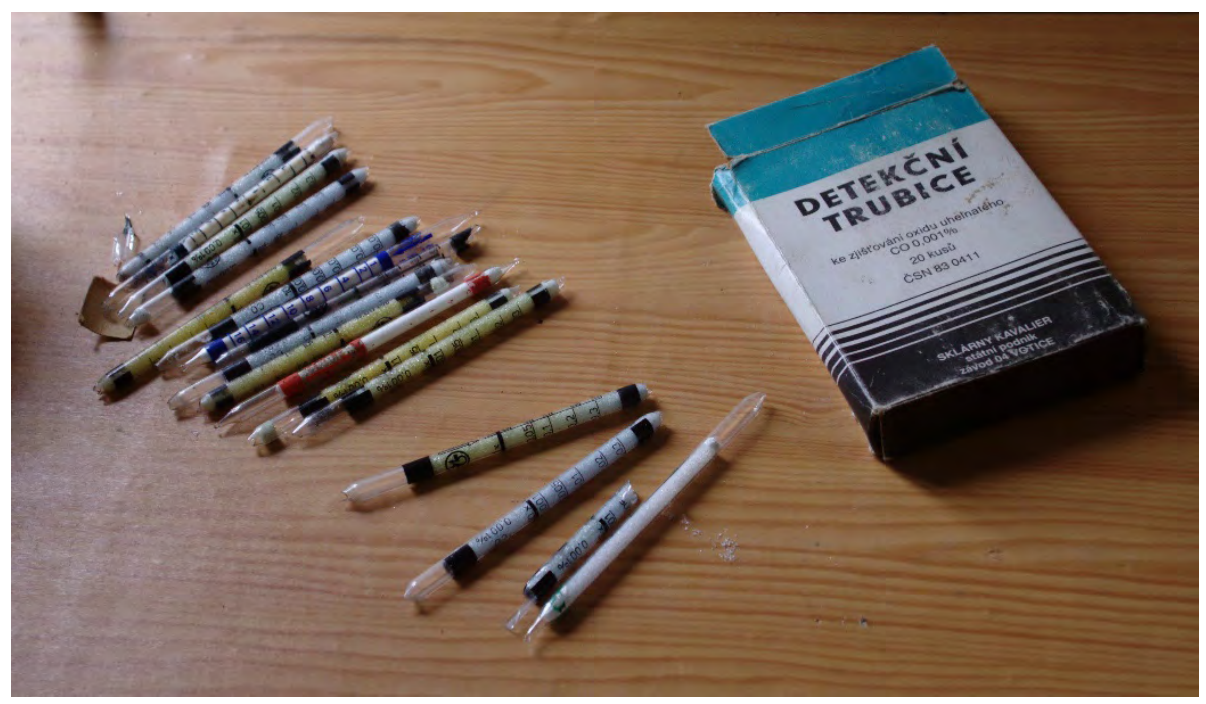

Figure 13. Detection tubes (author's photo)

Detection papers are used for qualitative analysis, and only give information about the presence of a particular chemical (not a whole group or class of chemicals). Detection tubes can aspirate an amount of air and can be calibrated (a set of scales can be seen in figure 13 above), giving quantitative or semiquantitative information about the concentration of the target chemical.

\section{Summary}

\begin{tabular}{|l|l|}
\hline \multicolumn{1}{|c|}{ Strengths } & \multicolumn{1}{c|}{ Weaknesses } \\
\hline No need for electrical equipment & Can only measure one chemical at a time \\
\hline Cheap and reliable & Operated manually \\
\hline Low probability of false alarms & \\
\hline Short detection time & \\
\hline
\end{tabular}




\subsubsection{Flame Photometric Detector}

Flame photometry is an atomic spectroscopy technique based on the light emission phenomenon of excited atoms, or clusters of atoms, as they return to lower energy states. This is a very important CWA detection technique that has been used successfully for a long time. The detection of characteristic light emission by excited sulphur and/or phosphorus atoms is used to identify CWAs. Most classic CWAs, such as the G-agents, V-agents, and sulphur mustard (HD), contain phosphorus and/or sulphur in their molecules. Detectors based on atomic spectroscopy technology can also be used to detect many TICs, if they contain phosphorus, sulphur, arsenic or other atoms that produce characteristic light emissions. Flame photometric detectors (FPDs) have been in use for as long as gas chromatographic and liquid chromatographic detectors. FPD instruments for field operations have portability and fast real-time analysis. Analysing a vapour sample with a handheld FPD does not require sample preparation, as it draws the sample directly from the surrounding air and provides a content analysis instantly. The only field FPD detectors available on the market are the AP4C and AP2C, made by the Proengin company.

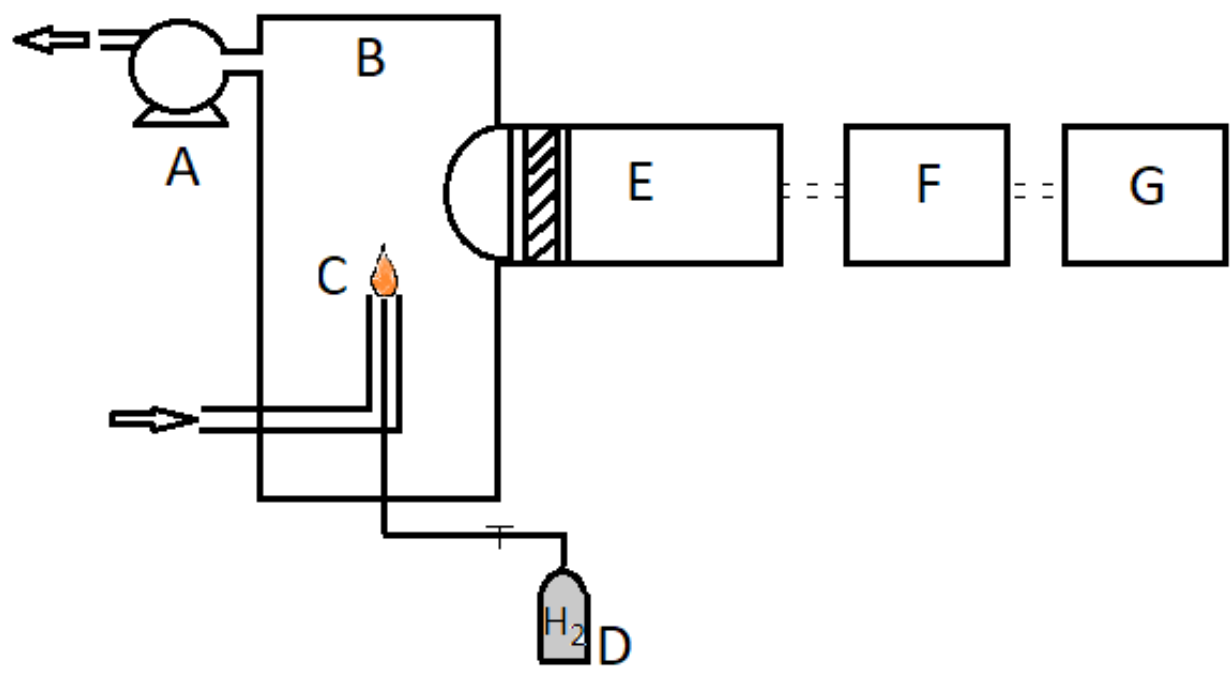

Figure 14. Principle of a Flame Photometric Detector's operation: A - pump, $\mathrm{B}$ - reaction chamber, $\mathrm{C}$ - flame, $\mathrm{D}-\mathrm{H}_{2}, \mathrm{E}$ - photometric sensor, $\mathrm{F}$ - electronics, $\mathrm{G}$ - visualization

Air samples are drawn in through an inlet and mix with hydrogen (D); at the end of the burner tip, the sample is burned. This causes CWAs or TICs containing phosphorus or sulphur to decompose and emit photons. These 
photons then go through the filter to the sensor (E), where they are detected. A signal is processed $(\mathrm{F})$, and the operator receives visual indication via a visible and/or audible signal.

Most FPD detectors are used in conjunction with separation techniques, such as gas chromatography (GC) and liquid chromatography (LC).

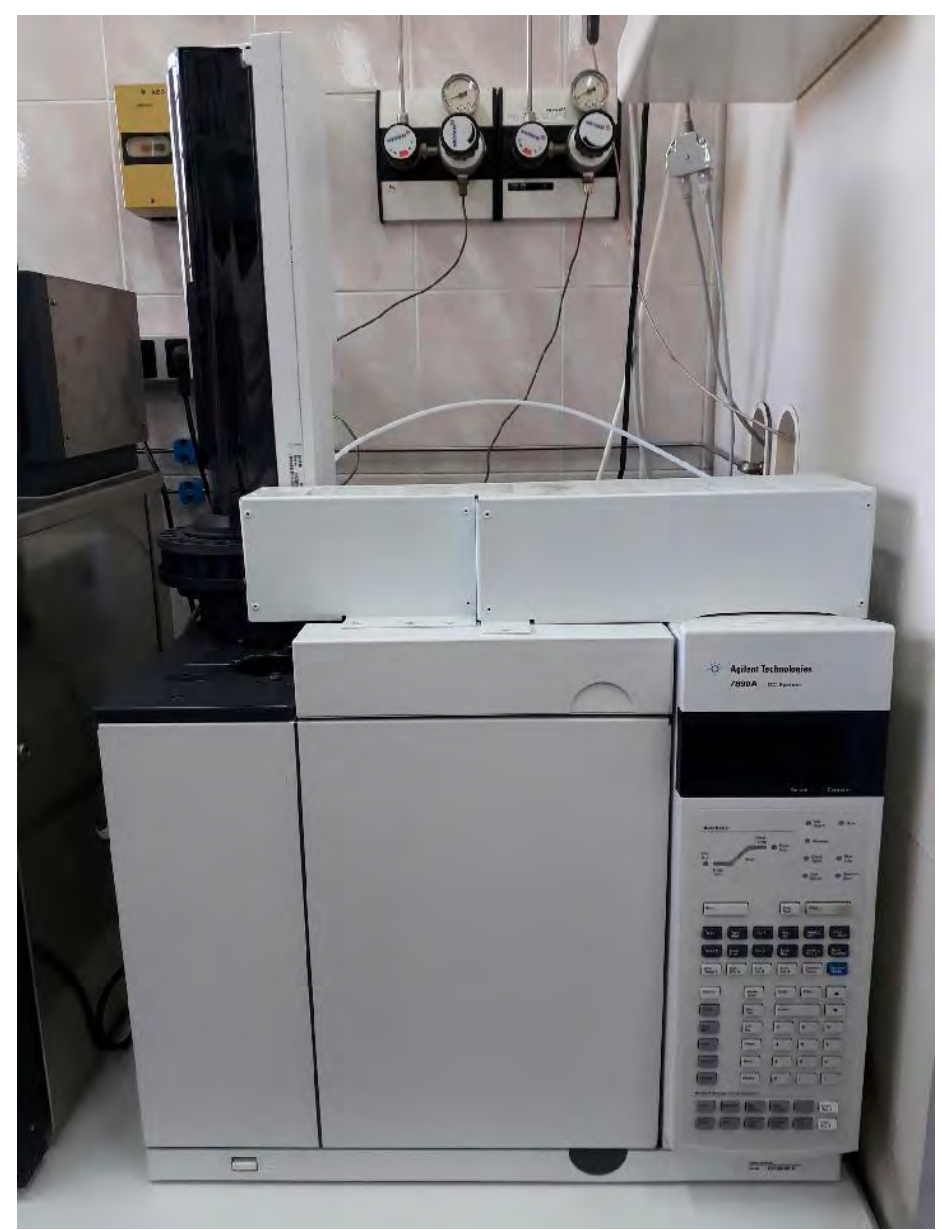

Figure 15. Agilent GC-FPD (author's photo)

Because of this, analyses are separated in time provide give additional parameters for identification - retention time or retention index. In the figure above, the FPD is equipped with a photomultiplier. This suggests that it only has one element detection capability (S or P). But if two photomultipliers are attached to the combustion chamber, both $\mathrm{P}$ and $\mathrm{S}$ could be detected simultaneously. 


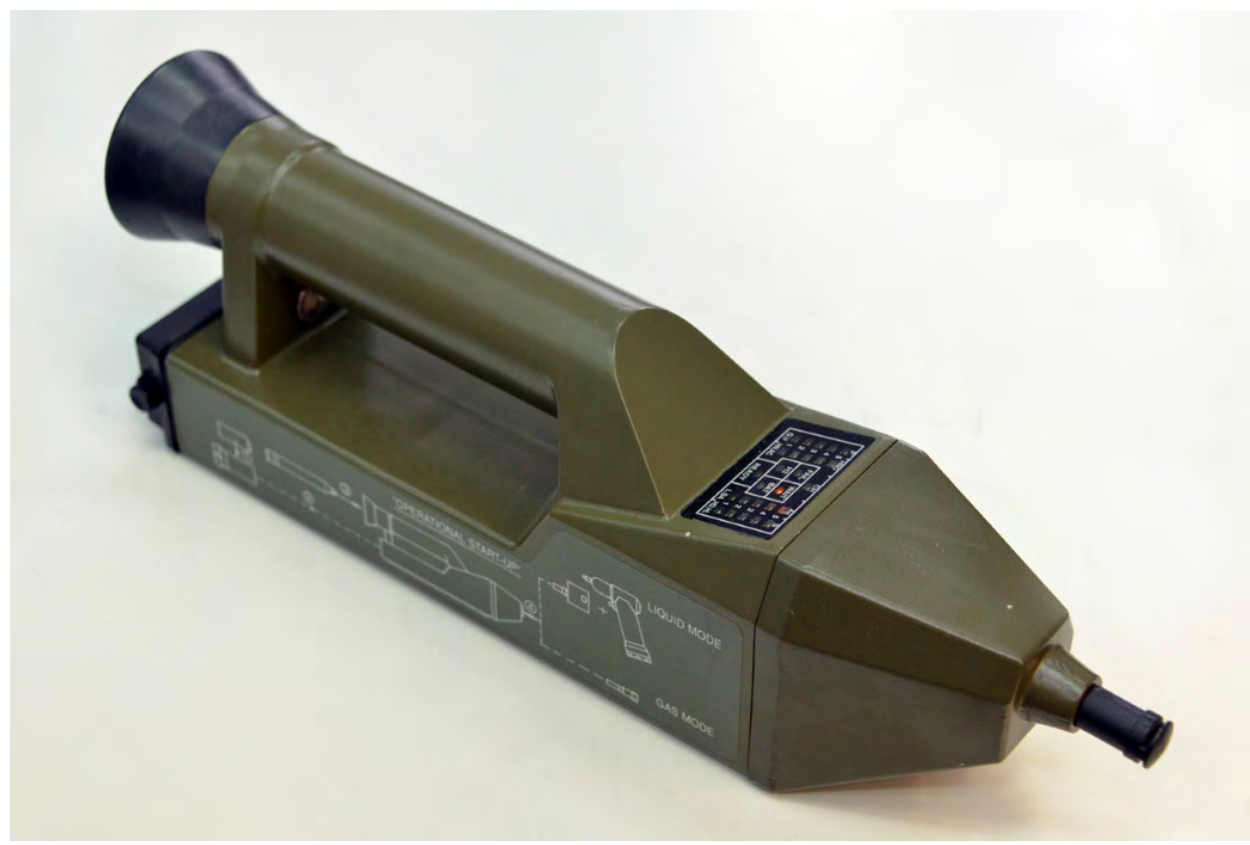

Figure 16. A Proengin AP4C FPD field detector, with an S4PE liquid sampler (author's photo)

Proengin's AP4C is the only field Flame Photometric Detector that can detect $\mathrm{S}, \mathrm{P}, \mathrm{As}$ and $\mathrm{N}$ chemicals. It is equipped with a sampler for liquids (or even solid surfaces, using wipes), for detection of persistent agents.

\section{Summary}

\begin{tabular}{|l|l|}
\hline \multicolumn{1}{|c|}{ Strengths } & \multicolumn{1}{c|}{ Weaknesses } \\
\hline Low detection limits & $\begin{array}{l}\text { Additional consumables are necessary - hy- } \\
\text { drogen canisters }\end{array}$ \\
\hline Short detection time & High false alarm rate \\
\hline Able to detect S, P, N and As agents & \\
\hline Can analyse wet wipes & \\
\hline
\end{tabular}

\subsubsection{Ion Mobility Spectrometry (IMS)}

Ion mobility spectrometry is an analytical technique used to separate and identify ionized molecules in the gas phase, based on their mobility in the carrier buffer gas. Mobility is defined as: 
$\mathrm{K}=\mathrm{v} / \mathrm{E}$, where $\mathrm{K}$ is mobility $\left[\mathrm{cm}^{2} /(\mathrm{Vxs})\right]$, $\mathrm{v}$ is drift velocity $[\mathrm{cm} / \mathrm{s}]$, and $\mathrm{E}$ is the electric field gradient $[\mathrm{V} / \mathrm{cm}]$.

Though heavily employed for military and security purposes, such as detecting drugs and explosives, the IMS technique also has many lab-based analytical applications, including analysis of both large and small biomolecules. IMS instruments are extremely sensitive stand-alone devices, but are often coupled with mass spectrometry, gas chromatography or high-performance liquid chromatography in order to achieve multi-dimensional separation. They come in various sizes, ranging from just a few millimetres to several meters, depending on the specific application, and are capable of operating under a broad range of conditions.

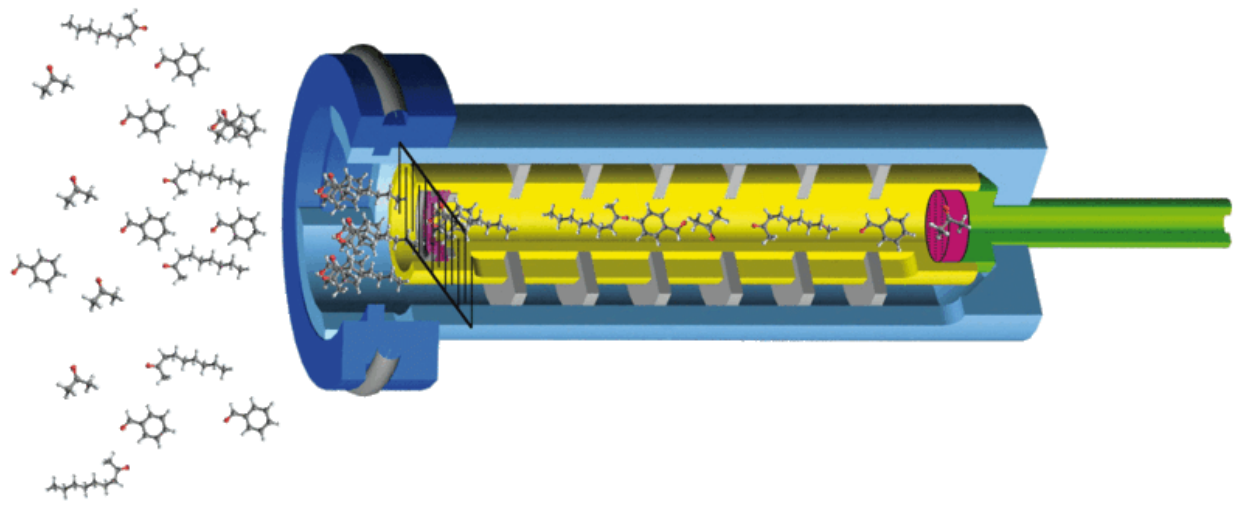

Figure 17. Principle of an Ion Mobility Spectrometry device's operation

Samples need to be in the vapour phase for detection by an IMS system. Vapour samples are analysed directly by drawing in sample flows containing the analyte of interest - CWAs, TICs and some volatile explosives can be detected in this way. Some samples, such as non-volatile explosives and many narcotic compounds, need to be heated to create enough vapour for detection. In this case, sample material released by thermal desorption is swept into the reaction region of the detector, usually by a small gas flow. IMS uses soft ionization techniques, such as $63 \mathrm{Ni}$ or corona discharge, to form reactant ion species from the carrier gas employed in the system, normally air. Mixing these stable reactant ion clusters with vapour samples to be analysed can result in ionisation of the sampled materials, thus forming ion clusters characteristic of the sampled material. This ionisation process is generally referred to as Atmospheric Pressure Chemical Ionization (APCI). 


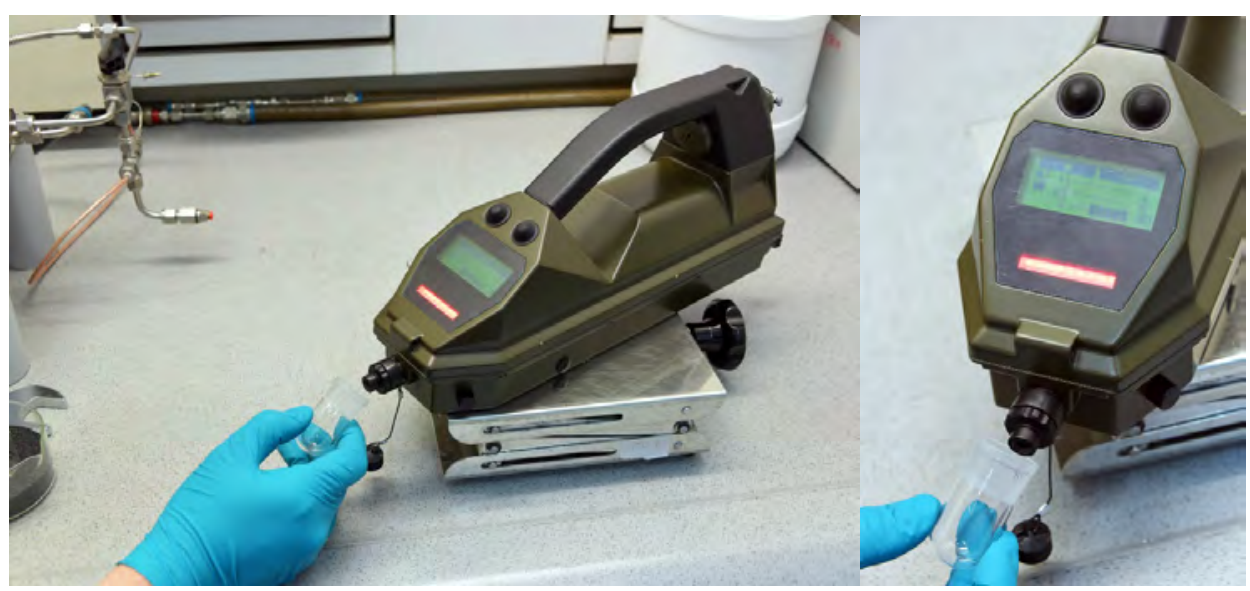

Figure 18. RAID M-100 (author's photo)

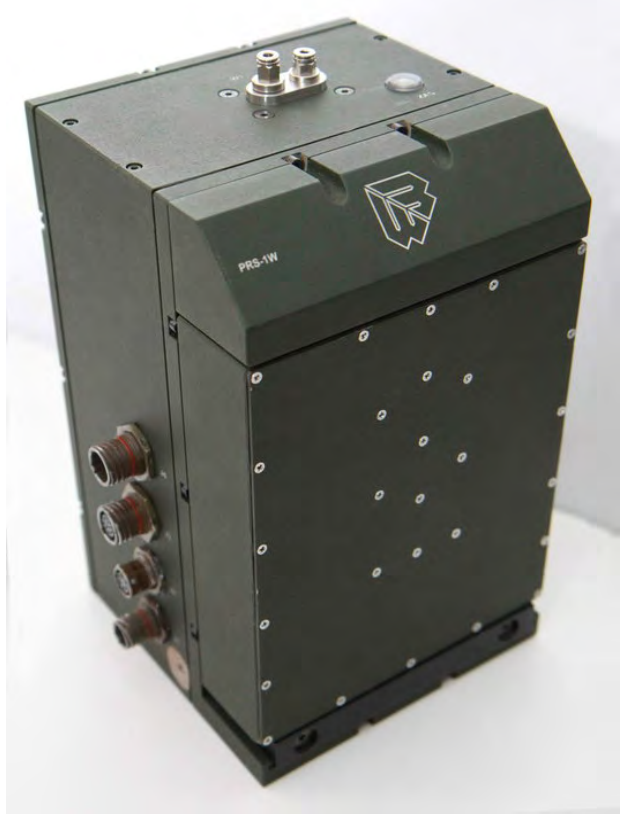

Figure 19. PRS 1W - Differential Mobility Spectrometer for CWA and TICs detection, for mounting in vehicles and fixed installations (author's photo)

The small packet of ions thus formed is injected electrically into a drift region, where they pass to a collector electrode some distance away (typically a few centimetres), under the influence of an applied electrostatic field. Ions travel through the drift region at speeds characteristic of the size and shape of 
the ion clusters. On arrival at the collector, each ion species generates a specific signal, and the ion current as a function of its arrival time is measured. A plot of ion current against $\mathrm{K}$ (mobility) forms an ion mobility spectrum, with an ion mobility band corresponding to each of the unique ionic species. The spectrum is a fingerprint of the parent compound. The measured IMS spectrum is then analysed and mobility information is extracted in real time, within the instrument. Comparison of measured mobility with the known mobility of threat compounds gives rise to an ALARM condition if there is a match.

There are many CWA detectors based on IMS technology. In fact, this technology can be divided into different subcategories (open loop technology, differential mobility spectrometry, and so on), but the basic principles are still the same. There are field, handheld, fixed, vehicle mounted and maritime IMS detectors available, for military and chemical safety applications.

\section{Summary}

\begin{tabular}{|l|l|}
\hline \multicolumn{1}{|c|}{ Strengths } & \multicolumn{1}{c|}{ Weaknesses } \\
\hline Low detection limits & Moderate to low (DMS) false alarm rate \\
\hline Short detection time & Low resolution power (except DMS) \\
\hline Ability to detect CWA and selected TICs & \\
\hline Simple operation and maintenance & \\
\hline
\end{tabular}

\subsubsection{Infrared spectroscopy}

Use of the IR technique for analysis and detection is based on the infrared absorption of the characteristics of a sample, at specific wavelengths. Function groups in a molecule vibrate at certain frequencies that fall within the IR's sensitivity. The molecule absorbs energy from IR waves that have the same frequencies, and so the vibrating function groups are excited to a higher energy level (specific function groups absorb IR radiation of specific frequencies). By determining the IR radiation frequencies being absorbed by the function groups composing the molecule, its molecular structure can be determined. The spectrum of a large molecule can then be matched with spectra from various databases.

Detectors based on IR technology have the advantage of reasonably high sensitivity and fast detection. Remote detection of chemical clouds can also be made using the infrared emission technique.

A sample is introduced to the spectrometer and exposed to IR radiation. The IR emission is filtered and certain well-defined wavelengths interact with the sample. When the sample contains targeted chemicals, absorption occurs. The intensity of radiation changes accordingly to the concentration of the chemical. By changing the wavelength of the radiation, the IR spectrum can be ascertained. Chemical 
analysis is made by for the checking presence of absorption at certain wavelengths, or by analysing the entire spectrum (which is time consuming).

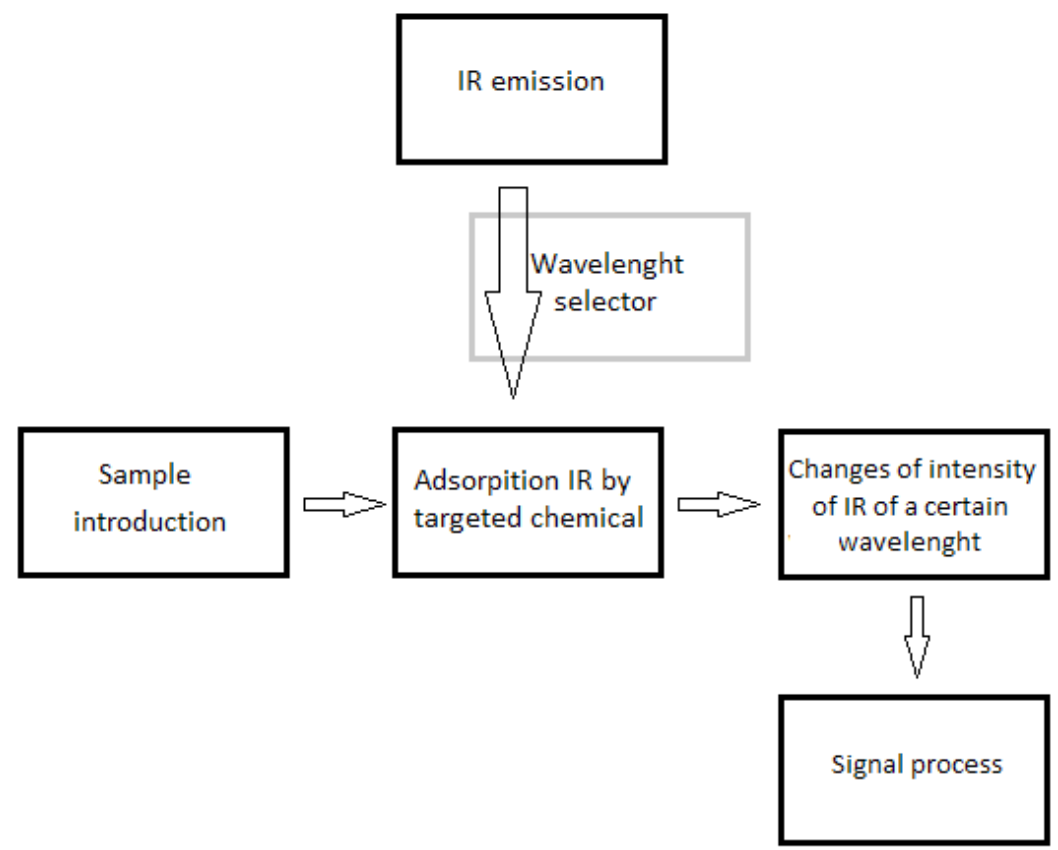

Figure 20. Block diagram of an IR detector

In more sophisticated detectors, known as Fourier transform infrared (FTIR) spectrometers, the entire IR spectrum can be collected and processed quickly. The heart of the FTIR detector is an interferometer (Michelson's is the most often used). The Michelson interferometer, illustrated in Figure 21, is composed of a beam splitter, a fixed mirror, and a moving mirror.

Incoming IR radiation is split into two beams that are reflected by the mirrors and then recombined before reaching the IR transducer. Changing the moving mirror's position enables the interference of the two beams to form an interferogram that is used to obtain the spectra. As Figure 25 shows, the IR beam (1) emitted from the IR source strikes the splitter, which then divides the beam into two beams ( 2 and 3 ). Due to the special properties of the splitter, about $50 \%$ of the incoming beam is reflected by the splitter toward the fixed mirror and the other $50 \%$ is allowed to penetrate the splitter to hit the moving mirror. These beams are reflected back by the fixed and moving mirrors toward the splitter. The splitter then reflects half of the beam from the moving mirror (4) to the transducer, and also allows the other half of the beam from the fixed mirror (5) to penetrate it. These two beams then recombine (6) and 
pass through the sample cell. The rest of the radiation that is reflected from both the moving and fixed mirrors penetrates the beam splitter in the direction of the radiation source. Therefore, only about half of the initial IR radiation goes through the sample cell and reaches the transducer. The recombination of the beams after the splitter and the sample cell results in the interferogram, which is a plot of the output power versus the difference $(\delta)$ in path lengths for the two recombined beams. The $\delta$ value depends on the relative position of the moving mirror. Since the radiation strikes the moving mirror and is then reflected back, $\delta$ is equal to two times the difference between the path lengths of the moving mirror and the fixed mirror. If the sample in the sample cell absorbs the incoming IR of certain wavelengths, a characteristic interferogram is generated. By applying the Fourier transform to the interferogram, a distinctive spectrum is then obtained.

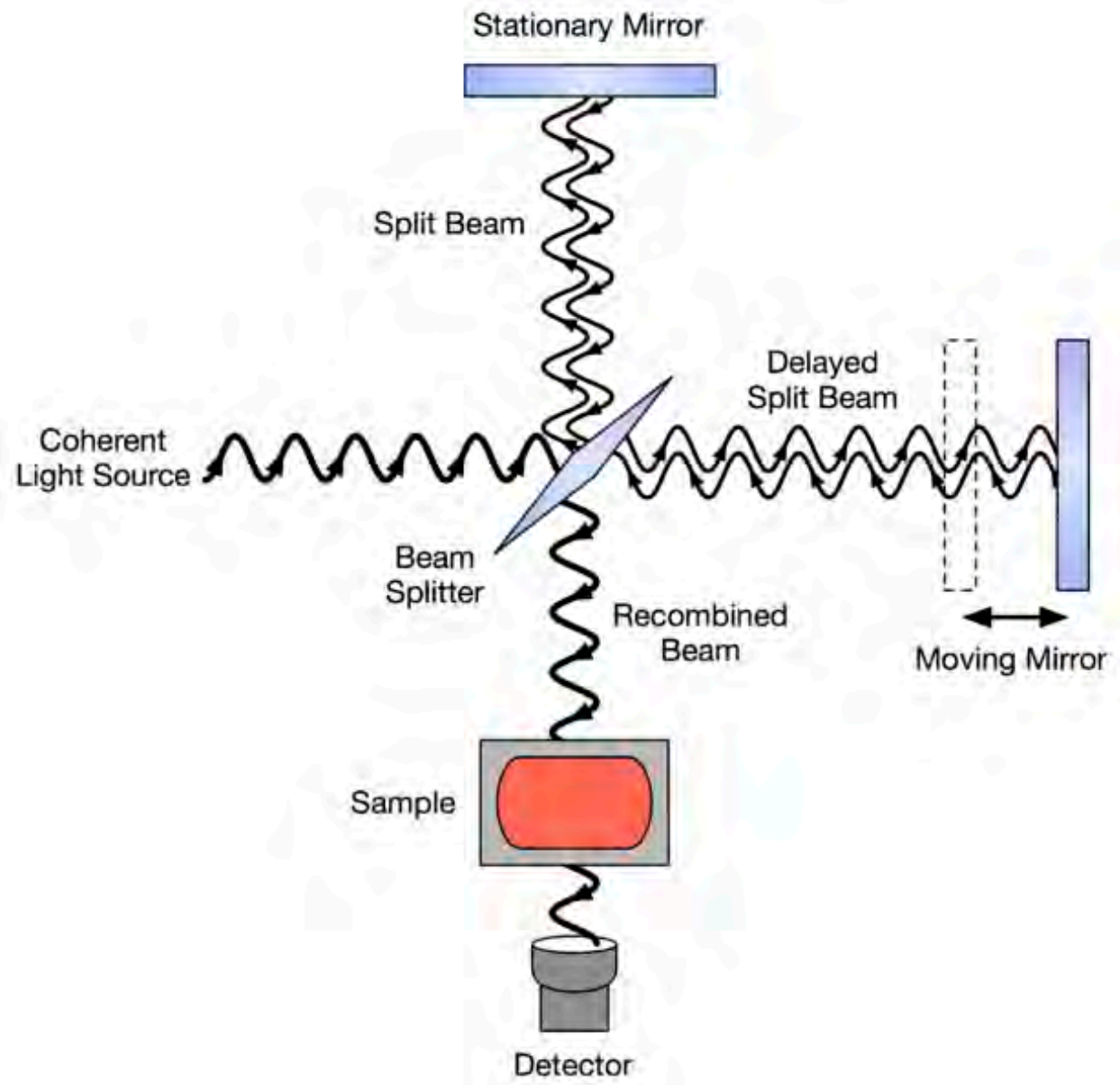

Figure 21. Schematic diagram of a Michelson interferometer 
IR technique has huge potential and has applications, both in laboratories and in the field. IR detectors can also be used with gas or liquid chromatography for separation of targeted chemicals, and measurement of a single compound instead of a mixture. For military and chemical safety and security purposes, IR equipment is mainly used for identification of chemicals.

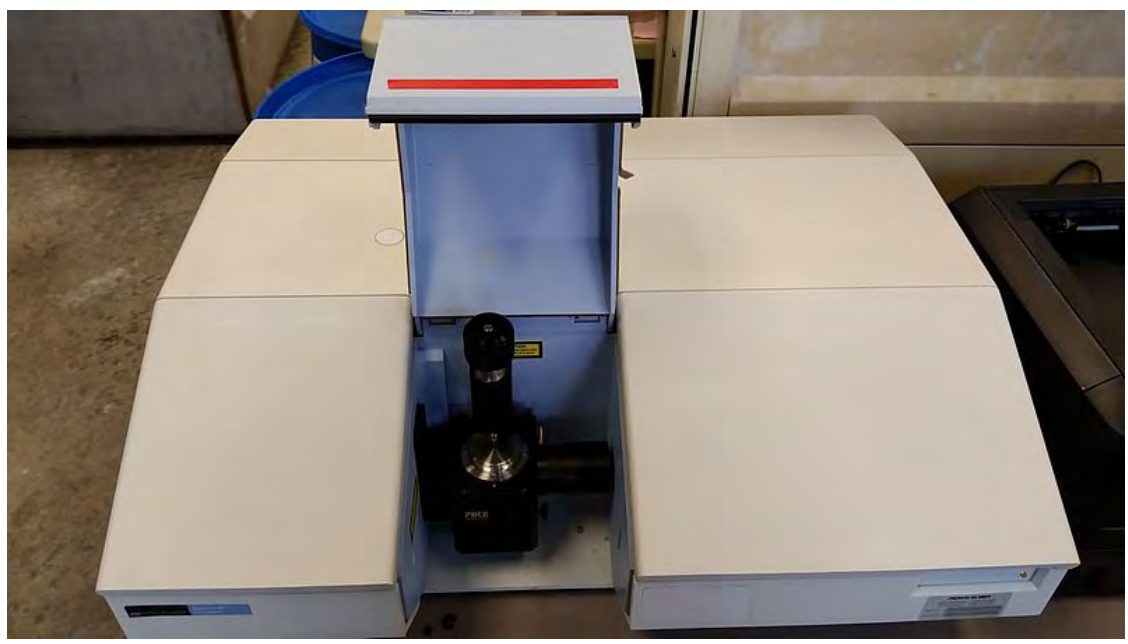

Figure 22. Spectrum BX FTIR Spectrometer (author's photo)

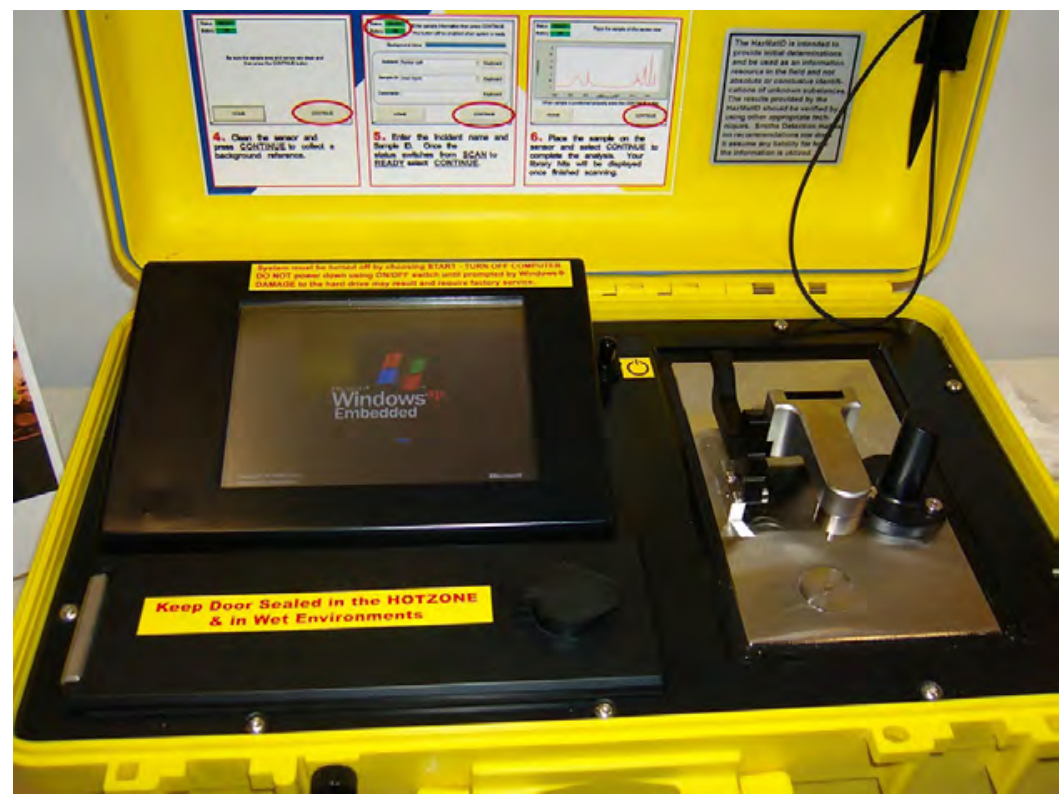

Figure 23. HazmatID detector (author's photo) 
The design of field-use FTIR detectors allows for their decontamination, making them usable in in hot zones. In most instruments, the user can create their own spectra library with chemicals of interest, to improving the instrument's applicability.

\section{Summary}

\begin{tabular}{|l|l|}
\hline \multicolumn{1}{|c|}{ Strengths } & \multicolumn{1}{c|}{ Weaknesses } \\
\hline Rich-information spectra & $\begin{array}{l}\text { Cannot analyse vapours and aerosols } \\
\text { (except Gas ID, which can analyse neither } \\
\text { liquids nor solids) }\end{array}$ \\
\hline Ability to analyse solids and liquids & High cost \\
\hline Strong identification capabilities & $\begin{array}{l}\text { Requires a highly-trained operator if } \\
\text { interpretation mode is used }\end{array}$ \\
\hline High resolution power & \\
\hline Low false alarm rate & \\
\hline
\end{tabular}

\subsubsection{Raman spectroscopy}

Raman spectroscopy is a technique that measures the energy of photons generated by the inelastic scattering of monochromatic excitation photons. During excitation, photons interact with the electron cloud of an analyte, and a small percentage of the photons undergo a change in energy as a result of the interaction. This energy change corresponds with molecular vibrations, rotations, and other low-frequency modes, and is plotted by instrumental operating software to produce a spectrum. Raman spectroscopy is often described as a complimentary technique to FTIR because both techniques are used to probe vibrational energy levels, although different selection rules allow FTIR and Raman to interrogate different sets of molecular vibrations. Raman scattering is an inherently low probability phenomenon, and as such the Raman scattering cross-section of a particular analyte will generally be several orders of magnitude less than the corresponding FTIR absorption cross-section. Practically, this means that the sensitivity of Raman spectroscopy is lower than FTIR spectroscopy. There are several advanced Raman spectroscopy techniques that generate a stronger Raman intensity when compared to spontaneous Raman scattering, such as Coherent AntiStokes Raman Spectroscopy (CARS), Resonance Raman Spectroscopy, Surface Enhanced Raman Spectroscopy (SERS), and Tip Enhanced Raman Spectroscopy (TERS). 


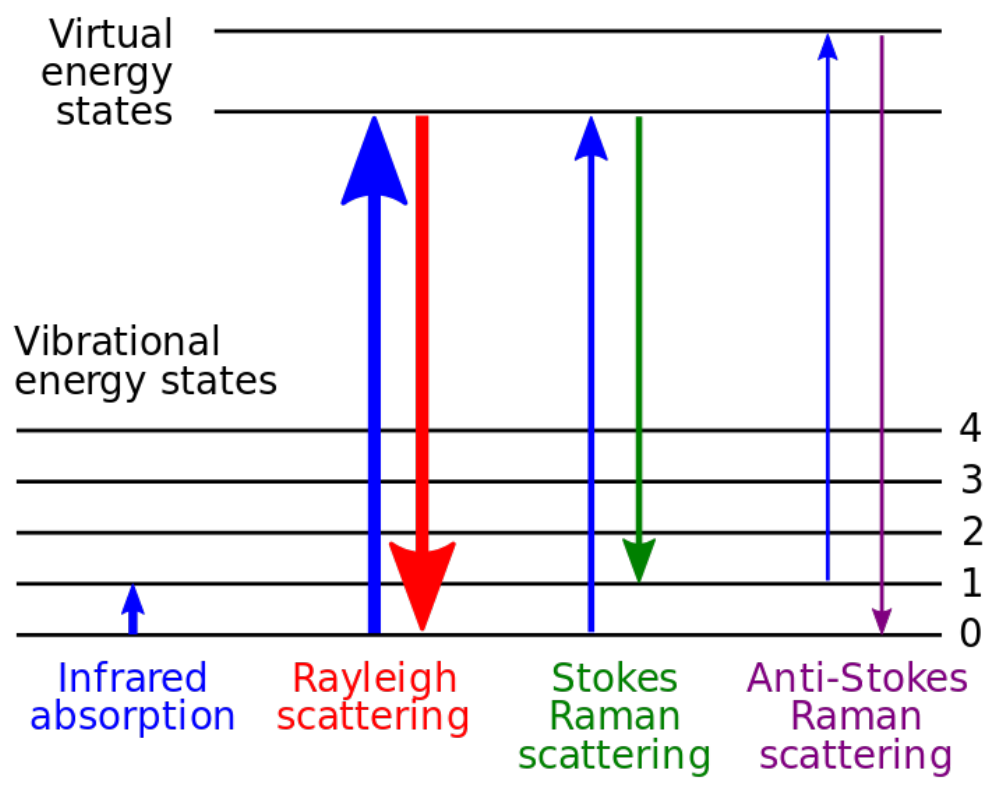

Figure 24. Raman Effect

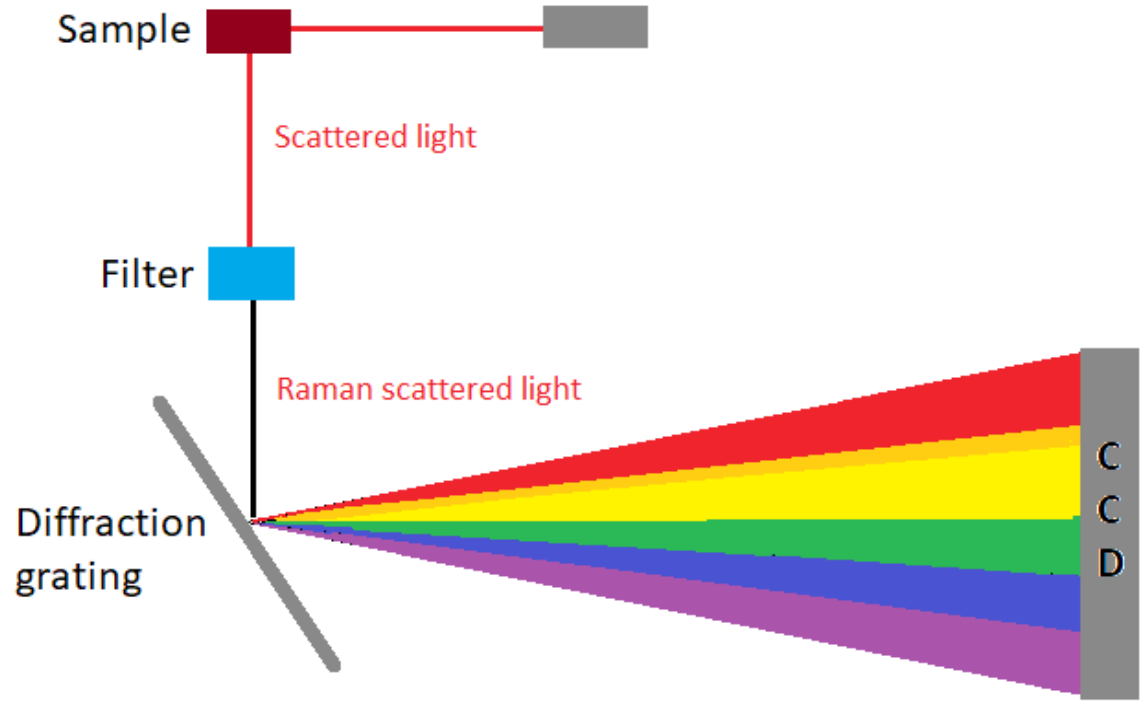

Figure 25. Simplified diagram of Raman spectrometer 
2. Detection of chemical contaminants

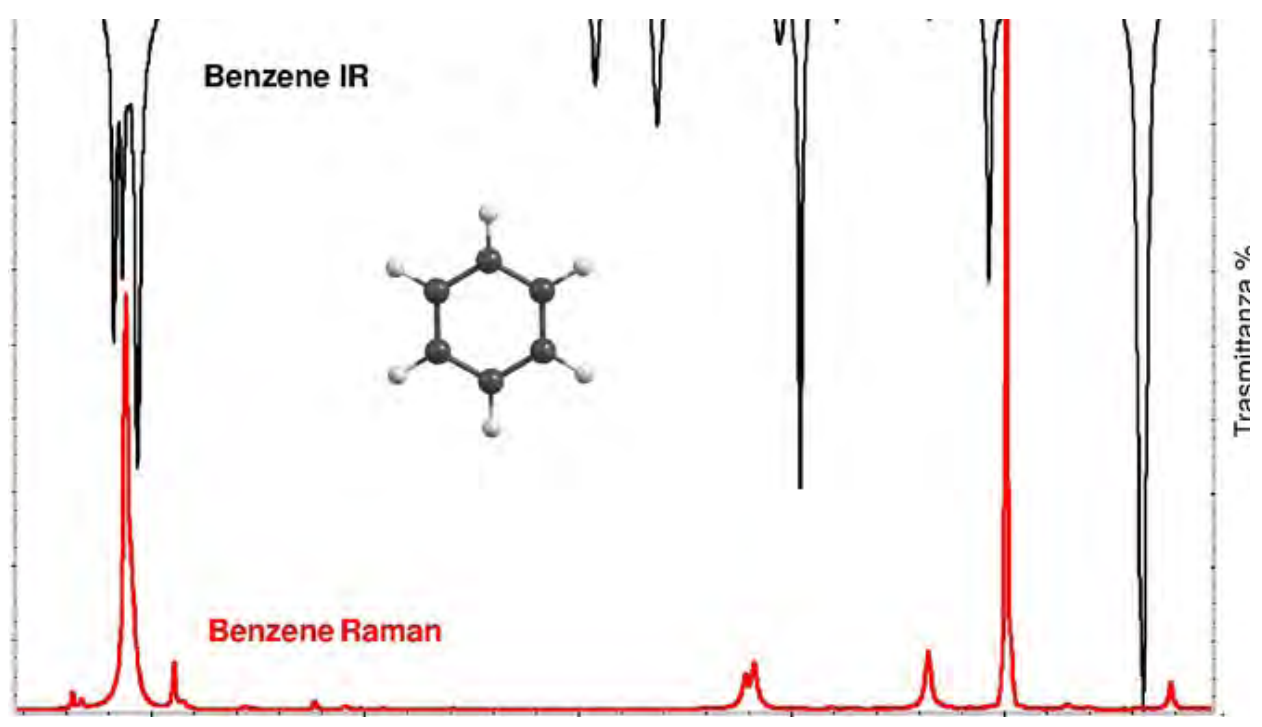

Figure 26. Raman spectrum of benzene

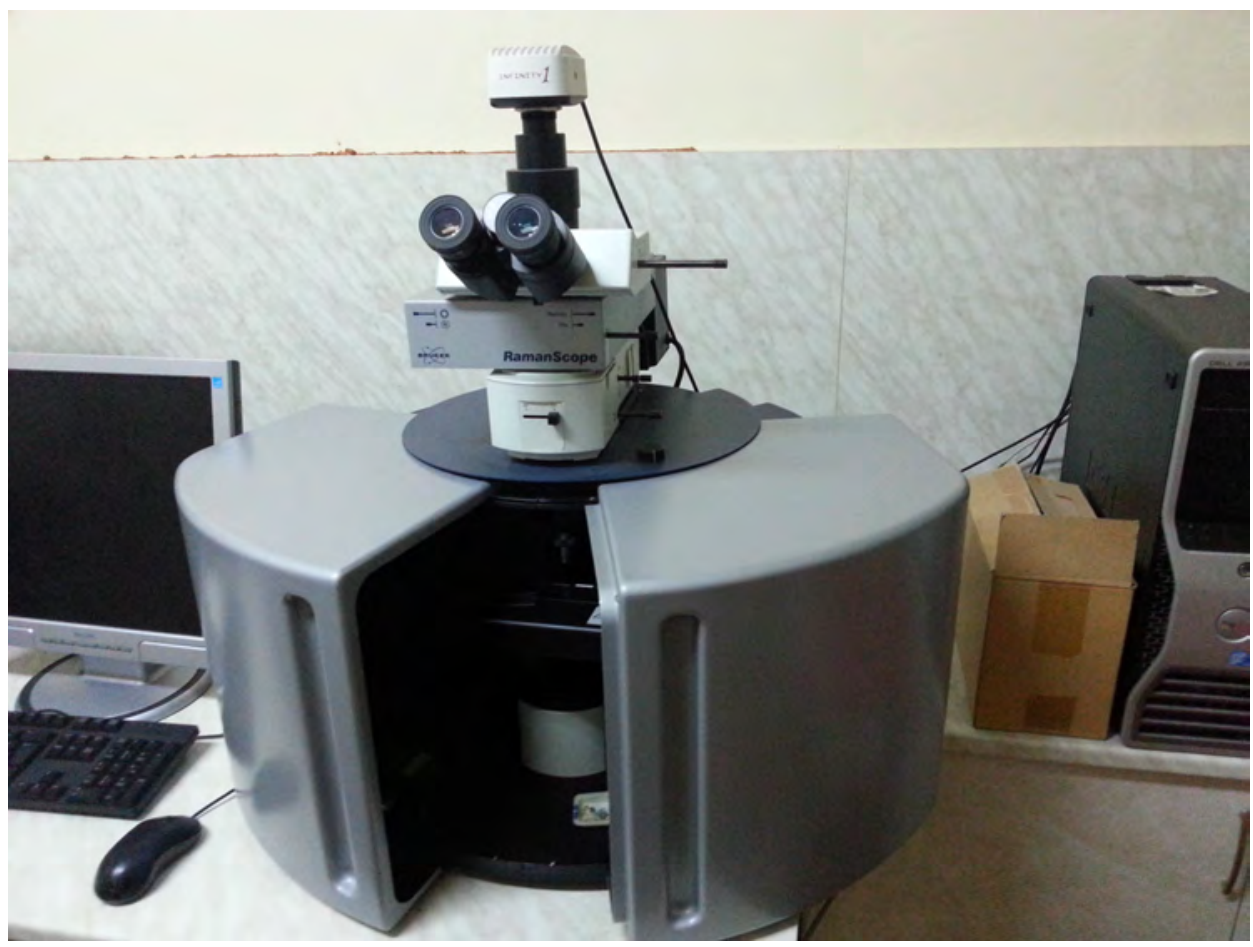

Figure 27. Bruker RamanScope III (author's photo) 
A sample is irradiated with monochromatic laser light, which is then scattered by the sample. The scattered light passes through a filter to remove any stray light that may have also been scattered by the sample. The filtered light is then dispersed by the diffraction grating and collected on the detector. The spectrum thus obtained is then compared with a built-in library.

This technique has powerful identification potential, and one very interesting feature of Raman spectroscopy is its ability to analyse samples through the transparent wall of container (glass, plastic, amber glass). This is especially important when dealing with dangerous chemicals. On the down side, Raman spectroscopy uses a strong laser beam that can initiate explosions when applied to explosive material. For this reason, field Raman detectors have an option for delayed measurement, to give the operator time to hide in case of an explosion. And because of this, only small amounts of unknown samples should be analysed at a time.

\section{Summary}

\begin{tabular}{|l|l|}
\hline \multicolumn{1}{|c|}{ Strengths } & \multicolumn{1}{c|}{ Weaknesses } \\
\hline Strong identification capabilities & High cost \\
\hline Ability to analyse solids and liquids & High detection limits \\
\hline $\begin{array}{l}\text { Ability to analyse through transparent } \\
\text { container walls }\end{array}$ & Probability of explosion initiation \\
\hline Low false alarm rate & \\
\hline
\end{tabular}

\subsubsection{Gas chromatography (GC)}

Gas Chromatography is a commonly-used analytical technique in many research and industrial laboratories, and is used for quality control as well as identification and quantitation of compounds in a mixture. GC is also frequently used in many environmental and forensic laboratories, because it allows for the detection of very small quantities. A broad variety of samples can be analysed as long as the compounds are sufficiently thermally stable and reasonably volatile.

A mobile and a stationary phase are required for this technique. The mobile phase is comprised of an inert carrier gas, such as helium, argon, or nitrogen. The stationary phase consists of a packed column in which the packing or solid support itself acts as the stationary phase, or is coated with a liquid stationary phase (high-boiling polymer). Most analytical gas chromatographs use capillary columns, where the stationary phase coats the walls of a small-diameter tube directly (e.g. a $0.25 \mu \mathrm{m}$ film in a $0.32 \mathrm{~mm}$ tube).

The separation of compounds is based on the different strengths of interaction of the compounds with the stationary phase (the 'like-dissolves-like' 
rule). The stronger the interaction is, the longer the compound interacts with the stationary phase, and the more time it takes to migrate through the column (longer retention time).

In a gas chromatography analysis, a known volume of a gaseous or liquid sample is injected into the head of the injector column, usually with a microsyringe, solid phase microextraction fibres or a gas source switching system).

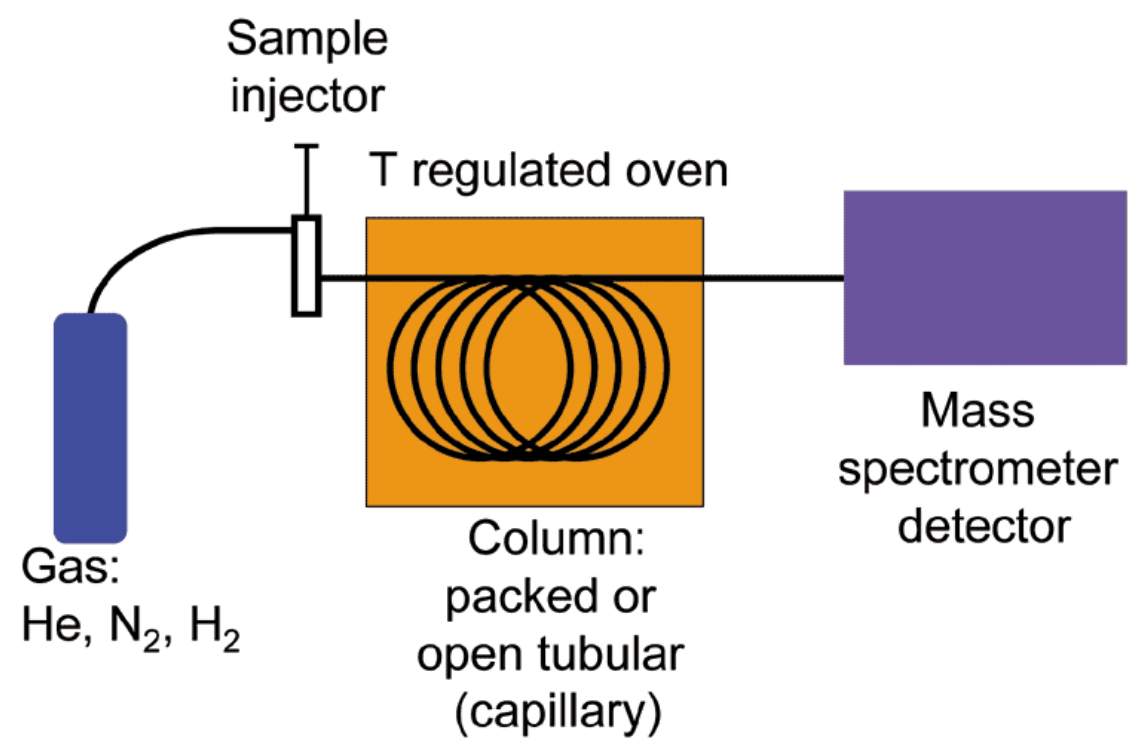

Figure 28. Principle of GC operation

As the carrier gas sweeps the analyte molecules through the column, this motion is inhibited by the interaction with the stationary phase. Since each type of molecule has a different rate of progression, the various components of the analyte mixture are separated as they progress along the column, reaching the end of the column at different times (retention time).

For example: If compound $\mathrm{X}$ interacts more strongly with the stationary phase than compound $\mathrm{Y}$, it lags behind compound $\mathrm{Y}$ in its movement through the column. As a result, compound $\mathrm{Y}$ has a much shorter retention time than compound X.

At the end of the column, a detector monitors the outlet stream. Thus, the time at which each component reaches the outlet and the amount of that component can be determined. Generally, substances are qualitatively identified by the order in which they emerge (elute) from the column, and by the retention time of the analyte in the column. Quantitative information is derived from the intensity of the signal generated by the detector. 
The amount of information generated by gas chromatography can be extended by use of different detectors. There are many types of GC detectors, and it is possible to connect them in parallel or series, with the restriction that the first one must not be destructive - like FPD or Raman.

Popular GC detectors for use in CWA analysis include:

- FPD - Flame Photometric Detector (P and S detection);

- NPD - Nitrogen-Phosphorus Detector (N and P detection);

- AED - Atomic Emission Detector (identifies atoms in molecules);

- ECD - Electron Capture Detector (detects electron-absorbing compounds, especially halogens);

- IR (FTIR) detector - Infrared detector (spectral technique for structural analysis, functional group identification and identification via library comparison);

- MS - mass spectrometer (spectral technique for structural and isoto; e analysis, and identification via library comparison (the largest spectra libraries are for mass spectra)).

$\mathrm{GC}$ is one of the most common chemical analytical techniques, and there are many types of GC systems. Most are designed for laboratory use, but there are also a significant number of mobile systems, some even mounted in military vehicles.

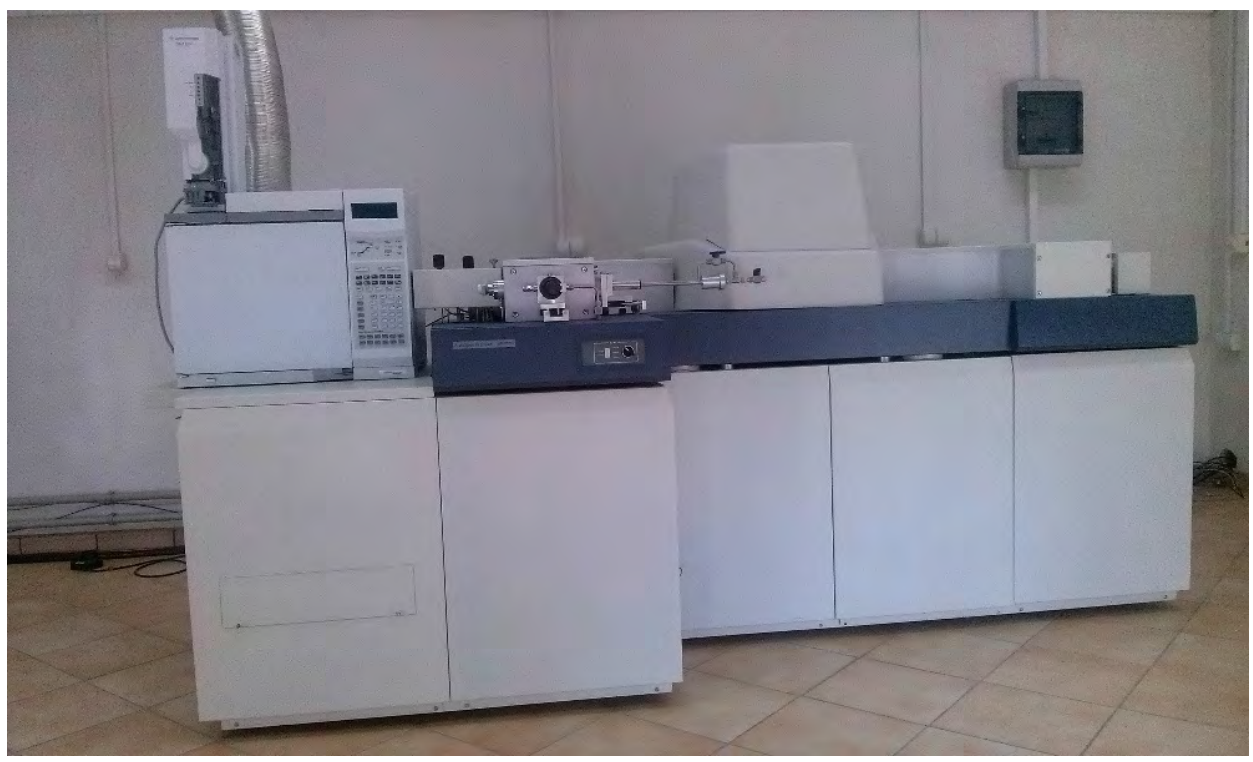

Figure 29. Micromass Autospec GC - HRMS (High Resolution Mass Spectrometer) (author's photo) 


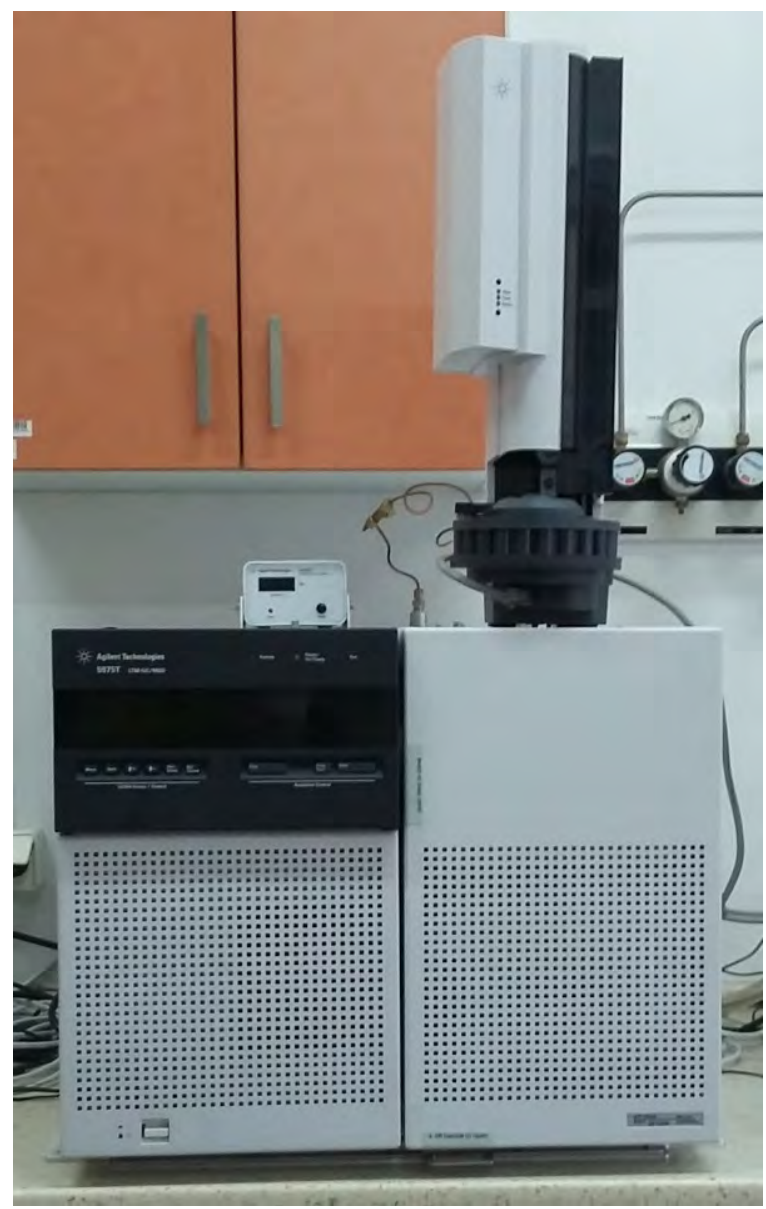

Figure 30. Agilent 5975T mobile GC-MS (author's photo)

\section{Summary}

\begin{tabular}{|l|l|}
\hline \multicolumn{1}{|c|}{ Strengths } & \multicolumn{1}{c|}{ Weaknesses } \\
\hline Strong identification capabilities & High cost \\
\hline $\begin{array}{l}\text { Ability to analyse all types of samples } \\
\text { after sample preparation }\end{array}$ & High maintenance cost \\
\hline Low false alarm rate & $\begin{array}{l}\text { Requires special gasses (helium, nitrogen, } \\
\text { hydrogen) }\end{array}$ \\
\hline Largest spectra libraries available & Requires highly-trained operators \\
\hline Very sensitive & \\
\hline
\end{tabular}




\subsection{Practical information for chemical mission preparations}

\subsubsection{Mission types}

Knowing and understanding what you are facing is key to successfully preparing to respond to a CBRN incident. First of all, there are two kinds of CBRN incidents:

- Accidental - an event caused by human error or natural or technological reasons (spills, accidental releases, leakage, equipment failure);

- Intentional - deliberately caused events, including:

- Criminal acts, such as deliberate dumping or release of hazardous materials to avoid regulatory requirements,

- Malicious but not politically motivated poisoning of one or more individuals,

- Terrorist acts inflicting serious harm on persons for political or ideological reasons.

In accidental CBRN events, the only hazard that is expected to be encountered at the scene is from the released chemicals. With an intentional incident, further hazards could be expected from the perpetrators. As such, external support from military or police units is needed to prevent further attacks and help contain the situation.

The next step after determining the cause of the incident is to classify the hazards involved, based on the nature of the agents used - whether Chemical, Biological, Radiological or Nuclear.

The third step in mission classification is determining the main purpose of the response. Is it a life-saving mission, or just a reconnaissance mission? The main difference between the two is time pressure. In life-saving missions, time is critical as hostages or injured and dying people are at stake. These kinds of missions tend to be fast-paced and require energy and stamina from the operators. In a reconnaissance or sampling mission, time is not such an important factor, and these missions are less energetic.

In either case, other than the time factor the safety of operators and security of samples taken, equipment and resources, etc, must also be taken into consideration. Forensic missions especially need to be well prepared and conducted with priority given to the quality of the evidence collected.

The type of mission being prepared for determines the clothing and equipment needed, as well as the amount of information that must be gathered before the mission begins, in order to better prepare for it.

\subsubsection{Sources of information}

There are many sources of information available to chemical teams before they arrive at the scene. Typically, a chemical reconnaissance team or Hazmat Team isn't the first on the scene - their first information is usually acquired from 
interviews with rescue teams, firefighters, police officers, factory staff, victims and witnesses. Speaking with medical staff and ambulance crews can help about the symptoms of the injured can also help identify chemical agents, or agent classes.

As discussed earlier, chemical transportation labelling can also help quickly determine the nature of the threat. Information from UN numbers or pictograms on tanks and containers can identify the chemicals involved. In accidental CWA incidents, the relevant indicators include:

- Numerous dead animals;

- Lack of insect life;

- Mass casualties;

- Unexplained physical symptoms;

- Pattern of casualties;

- Illness in a specific, confined geographic area;

- Unusual liquid droplets;

- Areas of dead vegetation;

- Unexplained odours;

- Numerous people experiencing blisters;

- Low-lying cloud/fog-like conditions;

- Unusual metal debris/bomb-like materials.

Other relevant information can include the location, number of people involved or living in the vicinity, weather conditions and other agencies present at the scene. Note that these can also be important factors in non-chemical incidents.

\subsubsection{Important detector parameters}

The different types of missions and the variety of possible agents at a scene make it impossible to have one detector for all threats. There are many detectors on the market and they vary in cost, performance and reliability. Choosing the proper device for each mission can be quite challenging. Many factors should be considered when selecting which detector to take, but two of the most important are:

- Detection capability (selectivity, sensitivity, response time etc.);

- Performance (warm-up time, calibration needs, portability, power requirements, etc.).

In more detail, some of these factors are:

Selectivity is the ability of a detector to respond only to the targeted chemicals in the sample. When a detector is set to detect G-agents, it should only respond to G-agents detected in the sample, regardless of how many other chemicals are present. For example, colorimetric detectors are highly specific detection devices and have higher selectivity, as they respond to a certain number of specific chemicals that they were designed to detect with little or no interference from other chemicals. 
More specific, selective detectors are limited in the number of compounds that can be added to their detection capability. Less-selective types of detectors can respond to more chemicals than selective detectors, but their responses cannot immediately be attributed to CWAs, TICs, or non-toxic substances.

Detectors working in a well-defined environment (i.e. a facility producing phosgene) can be more selective, because they are detecting a known chemical. In the case of checking for unknown agents, less selective devices could be a better option.

The Sensitivity of a detector or a method is the measure of its ability to discriminate between small differences in analyte concentration. The detector or method is more sensitive when a large change in signal intensity is observed for a small change in concentration.

Limit of detection (LOD) is the lowest concentration level that a detector can identify with a certain degree of confidence. There are many definitions of LOD, such as the concentration at which the response signal generated is three times the instrument noise level. Here, LOD is referred to as the minimum detection level (MDL) of concentration that will consistently cause the detector to ping. It is affected by background noise and blank signals, and may vary widely for different chemicals. Environmental and operational conditions can also drastically affect the LOD of a device. Manufacturers normally provide LOD information obtained under optimum conditions. Additionally, a good detector should provide a warning signal well before a dangerous concentration is reached, to permit proper retreat or evacuation. Each type of operational scenario can require a different $L O D$.

Response dynamic range is the concentration range between the limit of quantification (LOQ) and the limit of linearity (LOL). The LOQ is the lowest concentration at which quantitative measurements can be made. The LOL represents the concentration level at which the calibration curve departs from linearity. LOD and LOQ are different in that the LOQ is usually somewhat higher than the LOD. When the concentration of a sample exceeds the LOL of the detector, an increase in sample concentration may not be reflected in the observed or reported response. For an analytical instrument, response dynamic range is crucial. However, for a field instrument, simply detecting the presence of a toxic chemical in the air at a given concentration or higher, is more important.

Quantitative analysis capability is an important parameter for laboratory instruments, but fortunately, not so much for field equipment, as many factors (temperature, humidity, dust, wind speed) can influence the quality of measurements. For field use, semi-quantitative or just qualitative information about the presence of a target chemical above the LOD level is considered satisfactory.

False alarm rate. There are two types of false alarms. A false positive alarm (Type I error) occurs when a target chemical is detected that is actually absent 
from the sample. These alarms can be caused by various factors, depending on the specifics of the technique used. For example, phosphorus and sulphur compounds, such as pesticides, would generate a false positive CWA alarm when a flame photometric detector is used. Detectors are always at risk of yielding false positive alarms, since no detector can be made $100 \%$ selective to only the targeted chemicals.

A false negative alarm (Type II error) occurs when there is no detection of a target chemical that is indeed present in the sample. These responses are viewed as more problematic than false positives, because failure to produce a necessary alarm can lead to dangerous or disastrous situations. Causes of false negative alarms include:

- Changing environmental conditions;

- Humidity;

- The presence of other chemicals that interfere with normal detection capabilities;

- Detector malfunctions, such as improper calibration and detection algorithm deviations.

Response time is the time required for the detector to respond to the targeted chemicals after an analysis cycle is begun. The elapsed time until an alarm should occur after the detector is exposed to the targeted chemical at different concentration levels is another important factor. Responses to higher-level concentrations must be fast and immediate, whereas somewhat slower response times for very low concentration levels are acceptable. Some detectors require a certain amount of time before they can respond with any alarm. For example, detectors with a sample pre-concentrator and/or a gas chromatography (GC) column in front of the sensor will require more time for analysis than detectors without such attachments. Response time is a function of vapour concentration for most direct-detection gross-level alarm devices.

Resistance to environmental conditions, including temperature, humidity level, dust concentration in the air, wind, and levels of contamination can all drastically affect the performance of a detector. For military operations, temperatures in the field can range from $-30^{\circ} \mathrm{C}$ to $+50^{\circ} \mathrm{C}$, with relative humidity levels ranging from less than $10 \%$ to $100 \%$. It can also be very dusty, windy, and/ or the air may contain diverse pollutants at varying levels. Ideally, a field detector must be operable under all environmental conditions, and should maintain its designated functions regardless of field conditions.

It should be noted, then, that all existing commercially-available detectors are affected to one degree or another by environmental conditions. Operating temperatures and humidity ranges are usually specified in the instrument documentation, or are available from the manufacturers. However, other factors are not always so readily available. Determining whether a detector can operate in the intended environment is crucial in the process of selecting which devices to take. 
Setup time is the time needed to prepare the detector before it can even be powered up. For handheld detectors, the setup time is usually minimal because they are usually self-contained, with only the necessary batteries being separately serviceable parts.

Warm-up time is the time required for the detector to become ready for analysis after it has been turned on. This could range from a few seconds to half an hour or longer, depending on the ambient temperature and relative operational parameters of the detector type. In general, the device goes through an internal self-check protocol to satisfy pre-set parameter requirements before it is ready for analysis functions.

Recovery time is the time taken for a detector display to return to the baseline 'no response' value after being removed from the agent. With some instruments, the recovery time increases significantly after extended exposure to high concentrations of agent. Ideally a detector should recover in a short period of time (i.e. within minutes).

Calibration/verification of in field application - Proper detector functioning will often require verification of its capacity to perform upon each startup of the device. For a chemical detector, the process is confirmed using known, non-toxic chemicals to simulate the compounds to be targeted. Ideally, the proper operation of the detector can be verified with simple simulant checks that do not require complicated correlation and calibration procedures before each use.

Portability, or how easily a device can be transported, includes the portability of any extraneous, supporting equipment required for the detector's operation. Field detectors must also be durable enough to withstand transportation from place to place by ground, rail, water and air.

Power requirements determine the amount of energy consumed by the detector and the ease with which it can be re-charged or have its batteries replaced. The most common power supplies for field-deployable detectors are batteries, however some detectors require specifically designed batteries, and finding replacements or recharging spent batteries in the field can be quite difficult. Ideally, a detector should be operable through the use of two or more alternative power sources, and battery life must be sufficient to last an entire mission.

Ongoing costs associated with a detector should be carefully explored, and should include equipment purchases, maintenance and consumables.

\section{References}

Ganesan K., Raza S.K., Vijayaraghavan R., Chemical warfare agents, J. Pharm Bioallied Sci. Jul-Sep 2010, no. 2(3).

Mesilaakso M., Chemical Weapon Convention. Chemical Analysis, Sample Collection, Preparation and Analytical Methods, Wiley, USA 2005. 
Pitschmann V., Overall View of Chemical and Biochemical Weapons, Toxins (Basel) Jun 2014, no. 6(6).

Schulz-Kirchrath S., Compendium. Chemical Warfare Agents, OWR NBC Defense Systems, Germany 2006.

Sferopoulos R., A Review of Chemical Warfare Agent (CWA) Detector Technologies and Commercial-Off-The-Shelf Items, DSTO Defence Science and Technology Organisation, Australia 2009.

Somani Satu M., Chemical Warfare Agents, Academic Press, Inc. UK 1992.

Sun Y., Ong K.Y., Detection Technologies for Chemical Warfare Agents and Toxic Vapors, CRC Press, USA 2005.

http://www.chem.ucla.edu/ bacher/General/30BL/gc/theory.html at 28.07.2017

https://www.chemheritage.org/distillations/magazine/a-brief-history-of-chemical-war, at 16.06.2017

https://www.opcw.org/news-publications/publications/facts-and-figures/\#c1920 at 16.06.2017

https://en.wikipedia.org/wiki/Organisation_for_the_Prohibition_of_Chemical_ Weapons at 15.06.2017

https://en.wikipedia.org/wiki/List_of_chemical_warfare_agents at 16.06.2017

https://fas.org/programs/bio/chemweapons/cwagents.html at 16.06.2017 at 16.06.2017

https://www.opcw.org/about-chemical-weapons/types-of-chemical-agent/blood-agents/ at 14.06.2017

https://www.opcw.org/about-chemical-weapons/types-of-chemical-agent/riot-control-agents/ at 14.06.2017

https: / / www.smithsdetection.com/index.php?option=com_k2\&view=item \&id $=40$ \&Itemid=122 at 04.09.2017

https://chem.libretexts.org/Core/Physical_and_Theoretical_Chemistry/Spectrosco-

py/Vibrational_Spectroscopy/Raman_Spectroscopy/Resonant_vs._Nonresonant_Raman_Spectroscopy at 29.08.2017 